\title{
SOCIOSEMÁNTICA: \\ REFERENTES SUSTANTIVOS Y VERBALES \\ EN EL HABLA CULTA Y POPULAR \\ DE LA GIUDAD DE MÉXICO*
}

\section{INTRODUCGIÓN}

La sociolingüística se ha ocupado principalmente de estudiar las variantes formales del lenguaje en su dimensión social, pero no de la posible variación semántica!. En otros términos, a los investigadores les han interesado más los síntomas que los símbolos o referentes ${ }^{2}$, quizá porque la variación formal - sobre todo fonológica- - mas susceptible de ser tratada estadísticamente, lo que da como resultado una mayor objetividad y una mayor confiabilidad en el análisis.

En esta investigación intento mostrar que es posible analizar el significado a partir de datos léxicos que pueden ser tratados, en principio, estadísticamente. Con esa base, intento una interpretación del significado de los vocablos bajo la hipótesis de que existen diferencias sociosemánticas significativas entre dos grupos de hablantes de la ciudad de México.

* Ponencia para el Simposio "El español de América desde la perspectiva etnopragmática", $48^{\circ}$ Congreso Intemacional de Americanistas, Estocolmo, Suecia, 4 al 9 de julio de 1994 .

1 Véase, por ejemplo, Watrers 1988, p. 120; como él señala, la dialectología y la sociolinguistica se han enfocado iundamentalmente a hacer descripciones basadas en las variantes de forma. LAVANDFRA $(1984$, p. 15) señala, en relación con Labov, que él aplicó su modelo de variable língüística tanto al nivel fonológico como al sintáctico, e incluso al análisis del discurso. Sin embargo, las posteriores aplicaciones de otros "manejaron casi todas material fonológico". Cf. asimismo LAVANDERA 1988.

${ }^{2}$ Sobre las funciones sintomática y referencial del lenguaje, cf. JAKOBSON 1963, p. 214. Considero como equivalentes la función referencial y la simbólica, en el sentido en el que las utiliza BüHLER (1967, pp. 69 ss). La función referencial o simbólica es semejante a la que Halliday llamó "ideacional" (Halliday 1970, pp. 143 ss.) 
Mi planteamiento tiene antecedentes. Previamente hice dos investigaciones sobre una muestra formada por entrevistas que se grabaron en diferentes localidades de la república mexicana. Me apoyé en esas grabaciones para analizar los referentes de los sustantivos que se utilizaron en los estratos alto y bajo (Ávila 1991). Más adelante estudié, con esa misma muestra, los referentes verbales (Ávila 1993). Ahora utilizo un nuevo corpus: los materiales para el estudio del habla culta y popular de la ciudad de México ${ }^{3}$. Además hago un estudio más extenso que los anteriores. Por una parte, incluyo el análisis de la densidad léxica (cf. Ávila 1988b) y la longitud de los enunciados; y por otra - lo que intento por primera vez-, el de los referentes sustantivos y verbales.

\section{Procedimiento}

En los materiales mencionados se incluyen 32 entrevistas con informantes de nivel culto, y 33 de nivel popular, con tema libre. De ellas seleciont wlo las transcripciones de las grabaciones er las que d diálogo se establecía unicamente entre los informantes, stempre dos ${ }^{4}$. A esas caracteristicas correspondieron 10 entrevis. tas del nivel culto y 13 del nivel popular (véase tabla 1). El propósito de hacer esta selección fue el de analizar las conversaciones más naturales, en las cuales se pudiera encontrar un diálogo espontáneo, con una temática determinada sólo por los intereses de los participantes (véase tabla 1$)^{5}$.

3 Tomé los texios que analizo directamente de los libros publicados con esos materiales. Cif. Habla culta 1971 y Habia popular 1976. Los informantes cultos eran personas con estudios universitarios o equivalentes, fundamentalmente trabajadores no manuales, que podran incluirse en la clase media ilustrada de la ciudad. Ei nivel popular probabiemente está compuesto por trabajadores manuales con pocos estudios (cf. Habla popular 1976, p. 6). En relación con la clase media de México y su tipo de ocupación, cf. STERN 1990 , pp. 20 ss.

${ }^{4}$ En esas entrevistas no participaba el investigador o, si lo hacía, era sólo para estimular la conversación entre los informantes.

${ }^{5}$ Además, al ser igual la situación comunicativa - si se supone que condiciona en alguna medida el tipo de discurso o el tópico- se asegura una mayor similitud suponerse un mismo tipo de discurso, lo que permite una comparación más adecuada del habla culta y popular. Cf. para esto Albert 1972, p. 86; Hymes 1972, pp. 60 ss; y Hymes 1974, p. 53. 
TABLA 1

Habla culta y popular: entrevistas $e$ informantes

\begin{tabular}{lcc}
\hline Características & Habla culta & Habla popular \\
\hline Núm. de entrevistas & 10 & 13 \\
Núm. de informantes & 20 & 26 \\
Edad & & \\
18 a 30 años & 4 & 9 \\
31 a 40 & 3 & 5 \\
41 o más & 13 & 12 \\
Sexo & 7 & 15 \\
masculino & 13 & 11 \\
femenino & & \\
Diálogo entre & 5 & 5 \\
hombre y mujer & 1 & 5 \\
hombre y hombre & 4 & 3 \\
mujer y mujer & & \\
\hline
\end{tabular}

Todas esas entrevistas fueron procesadas por computadora. Twas wa widadosa revison y edoion', se andizaron en su

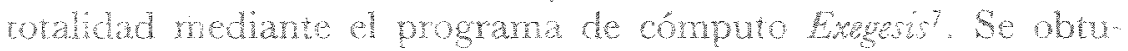
veron as las palabras gráncas de los dos coporé. Bl prograna asmimmo nos permitó asociar esas palabras gráhicas a sus tipos (palabras diferentes), y éstos a sus respectivos vocablos (entradas de diccionario o lemas) ${ }^{9}$. De esta manera pude hacer una evaluación de la riqueza léxica del habla culta y el habla popular.

Por otra parte - como he dicho antes-, decidí utilizar los corpora para hacer dos medidas estadísticas complementarias: la densidad y la longitud promedio de los textos. La densidad se

6 Los textos se recogieron mediante un scarner, lo que hizo necesaria su revision. Posteriomente heron editados para marcar toda la onomastica (nombres propios, de lugar y de instiuciones), ya que - con la excepción de los datos referentes a la longtud promedio de los chunciados- no se consideró en el anúlisis.

7 Elograma fue creado por $1 \mathrm{BM}$ de México espechicamente para $\mathrm{el}$ análisis y la interpretación de textos. Exegesis (1992) incluye los módulos "Densidad léxica" y "Longitud promedio del enunciado". Además permite asociar las palabras gráficas de un texto a sus tipos (palabras diferentes), y éstos a sus respectivos vocablos (o lemas), mediante la creación de bases de datos léxicas.

8 Cabe señalar que se omitieron en el proceso los pocos casos que correspondieron a parlamentos de los encuestadores.

9 En el análisis se omitieron todos los casos de nombres propios, de lugar y de instituciones. Es decin, se excluyó la onomástica. 
basa en el número de tipos o palabras diferentes que contiene un segmento de texto. En mi análisis utilizo segmentos de 100 palabras $^{10}$. La longitud de los enunciados se mide de acuerdo con el número de palabras que contiene cada uno ${ }^{11}$. En ambos casos se obtiene el promedio para los textos que se analizan ${ }^{12}$.

En cuanto al análisis del contenido, en principio se hizo-de nuevo utilizando el programa de cómputo- una recopilación de los sustantivos y los verbos de los dos estratos. A continuación se llevó a cabo una selección de los que se encontraban en un rango de frecuencias que iba de 10 a 200 en cada uno de los estra$\operatorname{tos}^{13}$. Sin embargo, dado que el límite inferior era muy bajo, podría resultar poco significativo. Por eso se incluyó la condición de que los vocablos deberían tener, además, una frecuencia total mínima de 15. Por otra parte, en el límite superior, aunque necesariamente la frecuencia de un vocablo debía ser menor a 200 en uno de los estratos, en el otro podia superar ese número-lo que ocurrió en unos pocos casos (véanse anexos 1 a 4 ).

Obtenidas así las listas de sustantivos y verbos, se hizo una comparación por egtrato - culto o poptalar-y por clases de palabras $^{14}$. Be buscó de esta manera recoger unxamente los vocablos en los cuales un estrato hubiera superado al otro por lo

10 Para la densidad léxica, cf. Ávnla 1988b, pp. 136 ss. En esa investigación demostré que hay una alta correlación entre la densidad y la riqueza de vocabulario.

${ }^{11}$ Una aplicación de la longitud promedio del enunciado en textos infantiles se encuentra en ÁviLA 1988a. Considero un enunciado como una secuencia de palabras que tiene como delimitadores, para decirlo brevemente, el punto (.) o los signos de admiración (:!) o interrogación ( $\dot{\imath}$ ?). Así se ha definido en el programa Exegesis mediante el cual hice los análisis de esta investigación. Cabe señalar que, como ha mostrado KLARE (1978, p. 269), la longitud de los enunciados es comparable con la complejidad de la oración: a mayor longitud del enunciado corresponde normalmente una estructura oracional más compleja.

12 Para el análisis de los enunciados se consideran todas las palabras del texto. En el de densidad se omite la onomástica.

${ }^{13}$ En mis investigaciones anteriores seleccioné diferentes rangos de frecuencias, de acuerdo con la exiensión de la muestra y la clase de palabra. De esta manera, cuando analicé los sustantivos de una muestra nacional (ÁvilA 1991, p. 281) utilicé el rango de 30 a 800 f́recuencias. Para el análisis de los verbos de la misma muestra, dado que el número de vocablos era menor, los seleccioné en el rango que iba de 20 a 800 frecuencias (Ávila 1993). En esta ocasión la muestra era de menor extensión, y por eso fue necesario modificar el rango de frecuencias.

14 De nuevo se utilizó un programa de cómputo diseñado exprofeso por María Pozzi, de El Colegio de México. 
menos en un $50 \%$ de frecuencias. En otros términos, si en el habla culta se utilizaba el vocablo alfa 60 veces, en el habla popular debió haber aparecido 90 veces - $50 \%$ más frecuentemente--, o bien 30 veces $-50 \%$ menos frecuentemente. Se procedió así para asegurar que la comparación de los sustantivos y verbos en cuanto a su frecuencia en cada estrato fuera estadísticamente significativa para cada uno de los vocablos ${ }^{15}$.

Ya establecido el conjunto definitivo (véanse anexos 1 a 4), se analizaron todos los contextos de cada uno de los vocablos ${ }^{16}$ : un total de 6916 para los 135 vocablos que se obtuvieron mediante el procedimiento descrito antes para los dos estratos (véanse tablas $5 a$ y $5 \mathrm{~b})^{17}$. De esa manera se establecieron las acepciones básicas o más frecuentes ${ }^{18}$, en las cuales se apoyan las clasificaciones del contenido que ofrezco más adelante. En un primer análisis, se clasificaron los vocablos de acuerdo con el hecho de que su referente fuera o no perceptible por los sentidos $^{19}$. El segundo análisis consistió en la clasificación del léxico obrenido en campos referenciales.

\section{Resurtanos}

\section{Riqueza léxica}

En las entrevistas de habla culta, para las 5 horas de grabación se recogieron 49873 palabras gráficas, 5124 tipos, y 3319 voca-

${ }^{15}$ En mis dos investigaciones anteriores (ÁvILA 1991 y Ávila 1993), puesto que, como he dicho, la muestra era mas extensa, seleccioné los vocablos que tenian 100\% de diferencia en las frecuencias de uso de los estratos que comparaba.

i5 Para estos análisis tuve la ayuda constante de Gerardo Aguilar, y la colaboración de Rubén Rivera, ambos del Centro de Estudios Lingüísticos y Literatios de Ell Colegio de México.

17 Al igual que en el número total de vocablos de los corpora, en la selección de los que tuvieron diferencia de más de $50 \%$ entre los dos estratos se recogieron más vocablos en el habla culta (81: 54 sustantivos y 27 verbos) que en el habla popular (54: 30 sustantivos y 24 verbos). Sin embargo, esto no afecta el análisis, pues se hizo, en cuanto a porcentajes y rangos (véase infra) siempre dentro de cada estrato.

18 Utilicé, entre otros, los siguientes diccionarios testigo: DEM 1986, DRAE 1992, y MOLINER 1983.

${ }^{19}$ Es decir, me basé en la posibilidad de que el referente pudiera ser percibido o no por la vista, el ódo, el tacto, el olfato o el gusto: cr. Ávila 1991, pp. 283 ss y 1993. 
blos; el habla popular, por su parte, produjo, para 6 horas y media de grabación, 45280 palabras gráficas, 4308 tipos, y 2375 vocablos (véase tabla 2 ).

TABLA 2

Habla culia y popular: longitud promedio de enunciados, densidad, palabras, tipos y vocablos

\begin{tabular}{lccccc}
\hline Caracteristicas & $\begin{array}{c}\text { Ing. prom. } \\
\text { enunciado }\end{array}$ & $\begin{array}{c}\text { Densidad } \\
\text { léxica }\end{array}$ & Palabras & Tipos & Vocablos \\
\hline habla culta & 10.9 & 63.7 & 49873 & 5124 & 3319 \\
habla popular & 5.1 & 61.3 & 45280 & 4308 & 2375 \\
\hline
\end{tabular}

De acuerdo con estos resultados, se puede advertir que en el nivel popular, no obstante que el tiempo de grabación fue mayor, se recogieron menos palabras gráficas que en el habla culta. Asimismo, la cantidad de tipos y de vocablos fue inferior a la del stro estrato. Compamatimente of habla wis prodio, para of

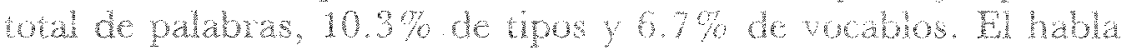
popular, por su parte, prodivo $9.5 \%$ ae ryos $5.2 \%$ de voca blos. En términos numéricos, en el habla culta se recogieron 816 tipos y 944 vocablos más que en el habla popular. Conforme a esto, el habla culta presentó más riqueza morfológica - reflejada en los tipos- y léxica - de acuerdo con el número de vocablosque el habla populạr (véase tabla 2).

Por otra parte, la longitud promedio de los enunciados en el habla culta fue de 10.9 palabras gráficas; y en el habla popular, de 5.120. La densidad en segmentos de 100 palabras grálicas resultó, para el habla culta, de 63.7, y para el habla popular, de 61.3. En otros términos, los enunciados en el habla culta tienen, en números redondos, el doble de palabras en promedio que los del habla popular. En cuanto a la densidad, la diferencia entre los dos estratos es asimismo significativa, y permite confimar que esa medida se correlaciona en alto grado con la riqueza léxica. En efecto, en una investigación previa (Ávila 1988, p. 144) pude hacer proyecciones de vocabulario con base en la densidad. Mis nuevos datos son muy semejantes a los anteriores, lo que

20 Estos resultados corresponden a la puntuación que hicieron los editores en las publicaciones que analizo: of. Habla culta 1971 y Habla popular 1976. 
confirma la posibilidad de usar la densidad de un texto como indicador para pronosticar la riqueza del vocabulario.

Contenido: perceptible vs. no perceptible

Ya en la dimensión del contenido, hice - como dije supra- dos clases de análisis. El primero, más general, se relaciona con la posibilidad de que los referentes de los vocablos sean o no perceptibles por los sentidos (cf. supra, y n. 19).

La primera clasificación se hizo con el propósito de buscar una diferenciación semántica general entre el habla culta y el habla popular (cr. la clasificación detallada en los anexos 1 a 4 ). Fn este tipo de análisis se advierten diferencias muy significativas entre los estratos (véase tabla 3). En los sustantivos, el habla culta utilizó tres veces más sustantivos con referente no perceptible (69\%) que el habla popular (23\%); y casi 2.5 más verbos de este tipo $(81 \%$ w. $33 \%)$. En cuanto al total de vocablos, el habla culta probujo 2.6 más vocablos de tipo to perceptble (73\%) one tha bia popula (28\%). Estos resulados muestran una distinch muy clara ente los dos tipos de habla: en nivel culto - para decirlo con otras palabras- el discurso es más abstracto que en el nivel popular, cuyos referentes son más concretos.

TABLA 3

Sustantivos y verbos: referentes no/sí perceptibles

\begin{tabular}{|c|c|c|c|c|c|c|}
\hline \multirow{2}{*}{$\frac{\text { estrito. }}{\text { refrite. }}$} & \multicolumn{3}{|c|}{ Habla culta } & \multicolumn{3}{|c|}{ Habla popular } \\
\hline & no peroppitide. & Spropopibies & Wial & no percopicisio. & Is seroctitides & total \\
\hline sustes. & $3769 \%$ & $1731 \%$ & $54 \quad 100 \%$ & $0723 \%$ & $2377 \%$ & $30100 \%$ \\
\hline verbos & $2281 \%$ & $0519 \%$ & $27100 \%$ & $0833 \%$ & $1667 \%$ & $24100 \%$ \\
\hline intal & $5973 \%$ & $2227 \%$ & $81100 \%$ & $1528 \%$ & $3972 \%$ & $54100 \%$ \\
\hline
\end{tabular}

Contenido: campos referenciales

El segundo análisis, más específico que el primero, se hizo - como he dicho supra- mediante la clasificación de los vocablos en campos referenciales. Para hacerlo - como he señalado previamente (Ávila 1991, p. 285)-comparé diferentes clasificaciones 
conceptuales $^{21}$. A partir de ellas, utilicé finalmente la que surgió internamente de los materiales objeto del análisis, la cual es básicamente la misma que empleé en mis investigaciones anteriores (Ávila 1991, 1993). Precisamente el hecho de que la clasificación se adecue a los vocablos del corpus y, como consecuencia, se haga a posterion es lo que distingue a los campos referenciales de los campos semánticos ${ }^{22}$. Además los primeros requieren, necesariamente, más flexibilidad que los segundos. Esto permite clasificar todos los referentes del corpus, a condición de mantener la congruencia ${ }^{23}$. De esta manera, consideré los campos referenciales que aparecen a continuación, en orden alfabético de siglas (véase además tabla 4):

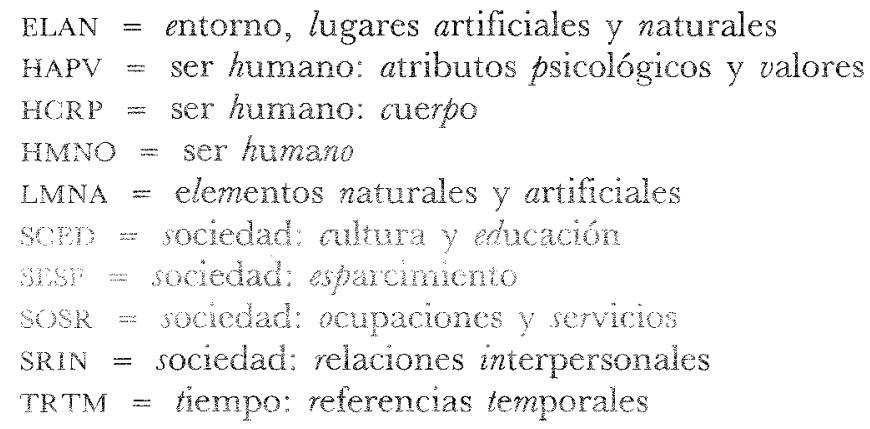

Los vocablos de los dos estratos fueron clasificados en uno de esos campos - reitero - con base en la acepción fundamental. Sin embargo, en algunos casos el vocablo admitía dos clasificaciones. En esa situación se consideró un segundo campo, que se indica en cada uno de los vocablos (véanse anexos 1 a 4$)^{24}$.

21 Entre ellas, las de Casares 1959, pp. xxxiii ss.; Dornseiff 1970, pp. 17-28; Dutchi 1962, pp. xxxvii ss.; Hallig \& Von Wartburg 1963, pp. 101-112; y MOLINer 1983, pp. xvi ss.

22 Para este tipo de análisis, of. Coskru 1964 y Potruer 1965. El analisis onomasiológico de los campos semánticos puede verse, por ejemplo, en Hegfir 1965 y Baldinger 1967 . Véase asimismo BaLdinger 1977.

23 Para intentar mi clasificación hice un solo conjunto del total de vocablos de los dos estratos. De esta manera aseguré la congruencia y evité el posibie sesgo de intentar una clasificación separada de los vocabios del habla culta y popular o de los verbos y los sustantivos.

${ }^{24}$ Puede considerarse que los contenidos forman una red de relaciones. En todo caso, mi clasificación ha tratado de hacer subconjuntos lo más extensos posibles, a partir de la acepción fundamental de cada vocablo. De esta manera se asegura una mejor comparación entre los subconjuntos léxicos de cada estrato. En otros términos, he buscado hacer una comparación funcionalmen- 
TABlA 4

Habla culta y popular: campos referenciales susiantivos y verbos

\begin{tabular}{|c|c|c|c|c|}
\hline \multirow[b]{2}{*}{ Campo referencial } & \multicolumn{2}{|c|}{ Mabla culta } & \multicolumn{2}{|c|}{ Habla popular } \\
\hline & Susiantivos & Verbos & Sustantivos & Verbos \\
\hline HMNO & mujer & & chiquillo & \\
\hline Ser humano & hombre & & chamaco & \\
\hline \multirow{8}{*}{$\begin{array}{l}\text { HAPV } \\
\text { Ser humano: } \\
\text { atributos } \\
\text { psicológicos } \\
\text { y } \\
\text { valores }\end{array}$} & \multirow{8}{*}{$\begin{array}{l}\text { razón } \\
\text { derecho } \\
\text { interés } \\
\text { idea } \\
\text { punto } \\
\text { amor }\end{array}$} & poder & miedo & \\
\hline & & deber & culpa & \\
\hline & & juzgar & & \\
\hline & & creer & & \\
\hline & & entender & & \\
\hline & & sentir & & \\
\hline & & acordarse & & \\
\hline & & encantar & & \\
\hline \multirow{5}{*}{$\begin{array}{l}\text { Wory } \\
\text { Ser humano: } \\
\text { cuento }\end{array}$} & & naces & gio & yer \\
\hline & & morir & & levantarse \\
\hline & & & & balar \\
\hline & & & & vamir \\
\hline & & & & comer \\
\hline \multirow{18}{*}{$\begin{array}{l}\text { scul } \\
\text { sociedad: } \\
\text { cultura } \\
\text { y } \\
\text { educación }\end{array}$} & cutwra & desarrollar & macsuro & explicar \\
\hline & educación & educar & prueba & terminar \\
\hline & carrera & estudiar & & \\
\hline & clase & preparar & & \\
\hline & nivel & leer & & \\
\hline & plan & escribir & & \\
\hline & aspecto & contar & & \\
\hline & problema & & & \\
\hline & ejemplo & & & \\
\hline & base & & & \\
\hline & cuestión & & & \\
\hline & caso & & & \\
\hline & tipo & & & \\
\hline & obra & & & \\
\hline & cosa & & & \\
\hline & escuela & & & \\
\hline & hogar & & & \\
\hline & iglesia & & & \\
\hline \multirow{4}{*}{$\begin{array}{l}\text { SRIN } \\
\text { sociedad: } \\
\text { relaciones } \\
\text { interpersonales }\end{array}$} & respeto & servir & compañero & plaricar \\
\hline & forma & cuidar & novio & buscar \\
\hline & manera & tratar & grupo & preguntar \\
\hline & falta & exigir & & ayudar \\
\hline
\end{tabular}

te adecuada para mis propósitos. Cr. LAVANDERA 1984, p. 45, quien propone un procedimiento que parece acercarse al que yo he seguido. 
TABLA 4 (concluye)

\begin{tabular}{|c|c|c|c|c|}
\hline \multirow[b]{2}{*}{ Campo referencial } & \multicolumn{2}{|c|}{ Habla culta } & \multicolumn{2}{|c|}{ Habla popular } \\
\hline & Sustantivos & Verbos & Sustantivos & Verbos \\
\hline & $\begin{array}{l}\text { matrimonio } \\
\text { marido } \\
\text { padre } \\
\text { madre } \\
\text { hijo } \\
\text { familia } \\
\text { gente } \\
\text { mundo }\end{array}$ & $\begin{array}{l}\text { necesitar } \\
\text { encontrar } \\
\text { oír } \\
\text { regalar }\end{array}$ & & quitar \\
\hline $\begin{array}{l}\text { SosR } \\
\text { sociedad: } \\
\text { ocupaciones } \\
\text { y } \\
\text { servicios }\end{array}$ & $\begin{array}{l}\text { profesión } \\
\text { médico } \\
\text { máquina }\end{array}$ & $\begin{array}{l}\text { dedicarse } \\
\text { valer }\end{array}$ & $\begin{array}{l}\text { comercio } \\
\text { mercado } \\
\text { kilo } \\
\text { peso } \\
\text { carro } \\
\text { camión }\end{array}$ & $\begin{array}{l}\text { comprar } \\
\text { vender } \\
\text { pagar } \\
\text { sacar } \\
\text { andar } \\
\text { partir }\end{array}$ \\
\hline $\begin{array}{l}\text { SEsp } \\
\text { sociedad: } \\
\text { cropamiento }\end{array}$ & $\begin{array}{l}\text { deporte } \\
\text { pelicula }\end{array}$ & $\begin{array}{l}\text { campo } \\
\text { cancion } \\
\text { grins }\end{array}$ & $\begin{array}{l}\text { campeonato } \\
\text { cquipo }\end{array}$ & $\begin{array}{l}\text { tocar } \\
\text { explorar }\end{array}$ \\
\hline $\begin{array}{l}\text { WAy } \\
\text { nntorno, } \\
\text { lugares } \\
\text { artificiales } \\
\text { y naturales }\end{array}$ & $\begin{array}{l}\text { mobiont } \\
\text { smatuon } \\
\text { vida } \\
\text { lugar } \\
\text { casa } \\
\text { país } \\
\end{array}$ & & $\begin{array}{l}\text { budbly } \\
\text { kilomero }\end{array}$ & \\
\hline $\begin{array}{l}\text { LMNA } \\
\text { elementos } \\
\text { naturales y } \\
\text { artificiales } \\
\end{array}$ & caballo & & $\begin{array}{l}\text { animal } \\
\text { perro } \\
\text { agua } \\
\text { piedra } \\
\end{array}$ & $\begin{array}{l}\text { agarrar } \\
\text { formar } \\
\text { abrir } \\
\text { tirar }\end{array}$ \\
\hline $\begin{array}{l}\text { TRTM } \\
\text { tiempo: } \\
\text { referencias } \\
\text { temporales }\end{array}$ & $\begin{array}{l}\text { época } \\
\text { edad } \\
\text { ocashón } \\
\text { momento }\end{array}$ & & $\begin{array}{l}\text { semana } \\
\text { domingo } \\
\text { noche }\end{array}$ & \\
\hline
\end{tabular}

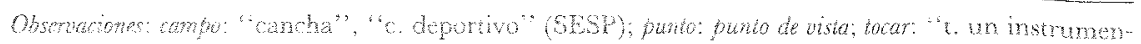

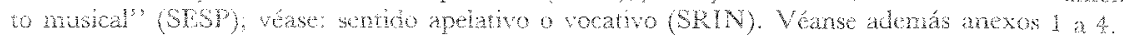

Los campos referenciales muestran que el habla culta tuvo un mayor número de vocablos en el de cultura y educación (SCED), con un total de 25; y menos en elementos naturales y artificiales (LMNA), con uno solo (véase tabla 5a). El habla popular, en cambio, tuvo más vocablos en ocupaciones y servicios (SOSR), con 12; y menos en lugares artificiales y naturales (ELAR), atributos psicológicos (HAPV) y en ser humano (HMNo), con sólo 2 vocablos en cada campo (véase tabla 5b). 
TABI A 5 a

Habla culta: vocablos, frecuencias y rangos por campos referenciales (véase explicación de * y siglas en T. 5b)

\begin{tabular}{|c|c|c|c|c|c|c|c|c|c|}
\hline$C R E F^{\prime}$ & $F P$ & $R A$ & $F C$ & $F T$ & $D F$ & $S R N$ & $\# V O C$ & $R P N$ & $\# R P$ \\
\hline ERAN & 296 & 5 & 110 & 406 & 186 & 183 & $6 \mathrm{~S}+0 \mathrm{~V}: 6$ & 30.5 & 7 \\
\hline HAPV & 787 & 3 & 301 & 1088 & 486 & 2,45 & $6 S+8 V: 14$ & $8.7^{*}$ & 1 \\
\hline HCRP & 48 & 9 & 15 & 63 & 33 & 21 & $0 \mathrm{~S}+2 \mathrm{~V}: 2$ & 10.5 & 4 \\
\hline HMNO & 380 & 4 & 73 & 453 & 307 & 25 & $2 S+0 V: 2$ & 12.5 & 6 \\
\hline LMNA & 17 & 10 & 00 & 17 & 17 & 38 & $1 \mathrm{~S}+0 \mathrm{~V}: 1$ & 38.0 & 9 \\
\hline$S C E D$ & 957 & 1 & 348 & 1305 & 609 & 582 & $183+7 V: 25$ & $11.6^{*}$ & 5 \\
\hline SESP & 58 & 8 & 00 & 58 & 58 & 76 & $2 \mathrm{~S}+0 \mathrm{~V}: 2$ & 38.0 & 8 \\
\hline $\operatorname{SOSR}$ & 109 & 6 & 6 & 115 & 103 & 87 & $3 S+2 V: 5$ & $8.7^{*}$ & 2 \\
\hline$S R I N$ & 815 & 2 & 236 & 1051 & 579 & 373 & $12 S+8 V: 20$ & $9.3 *$ & 3 \\
\hline TRTM & 71 & 7 & 33 & 104 & 38 & 157 & $4 S+O V: 4$ & 39.2 & 10 \\
\hline Total & 3538 & & 1122 & 4658 & 2411 & & $54 \mathrm{~S}+27 \mathrm{~V}: 81$ & & \\
\hline
\end{tabular}

TABLA 5 b

Habla popular, wacablos, frewencias y rangos por campos referenciales

\begin{tabular}{|c|c|c|c|c|c|c|c|c|c|}
\hline What & $F P$ & $R$ & Fe & $F$ & $D H$ & $B R$ & who & MW & F $R P$ \\
\hline HLAN & 34 & 9 & 8 & $\frac{15}{12}$ & 26 & 19 & $2 s+0 v: 2$ & 9.5 & 8 \\
\hline HAPV & 27 & 10 & 13 & 40 & 14 & 45 & $2 \mathrm{~S}+0 \mathrm{~V}: 2$ & 22.5 & 10 \\
\hline$H C R P$ & 416 & 2 & 193 & 609 & 223 & 86 & $1 \mathrm{~S}+5 \mathrm{~V}: 6$ & $7.2^{*}$ & 5 \\
\hline HMNO & 49 & 8 & 6 & 55 & 43 & 11 & $2 \mathrm{~S}+0 \mathrm{~V}: 2$ & 5.5 & 2 \\
\hline LMNA & 155 & 5 & 51 & 206 & 104 & 127 & $4 \mathrm{~S}+4 \mathrm{~V}: 8$ & $7.9^{*}$ & 6 \\
\hline$S C E D$ & 92 & 6 & 29 & 121 & 63 & 56 & $2 S+2 V: 4$ & $7.0^{*}$ & 4 \\
\hline$S E S P$ & 169 & 4 & 26 & 195 & 143 & 95 & $5 \mathrm{~S}+2 \mathrm{~V}: 7$ & $6.8 *$ & 3 \\
\hline$S O S R$ & 532 & 1 & 112 & 644 & 420 & 123 & $6 \mathrm{~S}+6 \mathrm{~V}: 12$ & $5.2^{*}$ & 1 \\
\hline SRJN & 174 & 3 & 81 & 255 & 93 & 146 & $3 \mathrm{~S}+5 \mathrm{~V}: 8$ & $9.1 *$ & 7 \\
\hline TRTM & 68 & 7 & 23 & 91 & 45 & 51 & $3 \mathrm{~S}+0 \mathrm{~V}: 3$ & 17.0 & 9 \\
\hline Total & 1716 & & 542 & 2258 & 1174 & & $30 S+24 V: 54$ & & \\
\hline
\end{tabular}

* El RPN se obtuvo de dividir la SRN entre el núm. de vocablos. En los campos donde hubo $\mathrm{S}$ y $\mathrm{V}$ el resultado se dividió entre 2. Cuando el RPN resultó idéntico en dos campos, se dio un \#R nás aflo al campo que tenía més vocablos.

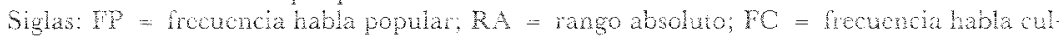
ta; $\mathrm{FI}=$ freckencia total; DF = diferencia de frecuencia entre h, jopular y culta $(\mathrm{o}$ entre $\mathrm{b}$ culta y popular en tabla 5a); SRN = Suma de los rangos de los vocablos del campo; \#VO = núm de vocablos $(S=$ sustantivos, $V=$ verbos $) ; R P N=$ rango ponderado; $R P V=$ núm de rango ponderado, expresado en enteros.

La clasificación de vocablos en campos da una idea de los conceptos que más se utilizan en el habla culta y popular de la ciudad de México. Sin embargo, es preciso matizar este primer enfoque, ya que es posible que algunos vocablos se concentren en unos pocos hablantes, y no sean representativos de su estrato 
social ${ }^{25}$. Por eso resulta necesario tomar en consideración las frecuencias y la dispersión de cada campo referencial, y no de cada vocablo. Con ese propósito ordené los campos según dos tipos de rangos: el absoluto y el ponderado.

\section{Campos referenciales y rangos}

El rango absoluto indica qué campo fue más frecuente en el habla culta o en el habla popular, sin considerar las diferencias entre ellas, ya que se basa en las frecuencias totales de cada campo $^{26}$. El rango ponderado, en cambio, atiende a las diferencias entre los dos estratos, así como al hecho de que en un determinado campo se hubieran utilizado las dos clases de vocablos ${ }^{27}$. A partir de estos rangos, se pueden señalar las diferencias sociosemánticas más significativas entre los dos estratos que comparo (véanse tablas $5 a$ y $5 b, 6 a$ y $6 b$ ).

Conforme al rango absoluto (RA), las personas más instruidas hablan sohre todo de culura y ednoción (BCD. $\mathrm{kA1}$ ), de sus relaciones con los demás (SRN kA2), y uthizan un buen rumero de téminos referidos a atributos psicologicos y valores (HApv:

25 En efecto, al estar limitada mi muestra en cuanto al número de personas encuestadas, no era posible evitar la concentración de unos pocos vocablos. Este hecho - que advertí en algunas entrevistas durante el análisis - me condujo a evaluar los campos referenciales y comparar el habla culta y popular a partir de ellos.

${ }^{26} \mathrm{El}$ rango absoluto se obtiene sumando las frecuencias de los vocablos de cada campo referencial. El rango más alto (número 1) corresponde al campo en el que hubo más frecuencias, y el más bajo (número 10), al campo donde se presentaron menos frecuencias (véanse tablas $5 a$ y $5 b$ ).

27 Para obtener el rango ponderado se consideran las diferencias de frecuencia de cada vocablo en los dos estratos, lo que produce una diferencia porcentual a favor del estrato en el cual un determinado vocablo fue más frecuente (véanse anexos 1 a 4 ). A esta diferencia porcentual de cada vocablo a favor del habla culta o del habla popular se le asigna un rango: el más alto (número 1) corresponde a la mayor diferencia. A continuación se suman los rangos de los vocablos de cada campo referencial. Este resultado se divide entre el número de vocablos del campo para obtener el rango del campo. Si un determinado campo tiene dos tipos de vocablos (sustantivos y verbos) el resultado se divide entre dos. Al número que se obtiene se le asigna un entero: el rango 1 corresponde al resultado más bajo (pero al rango más alto), y el 10 al más alto (que corresponde al rango más bajo). En los casos de igualdad de resultados, se asignó un rango superior al campo donde hubo más vocablos (véanse tablas 5 a y $5 \mathrm{~b}$ ). 
TABLA $6 \mathrm{a}$

Campos referenciales: rangos ponderado y absoluto

\begin{tabular}{lcclccc}
\hline & \multicolumn{2}{c}{ Habla culta } & & \multicolumn{2}{c}{ Habla popular } \\
\cline { 2 - 3 } \cline { 6 - 7 } Campos & Ponderado & Absoluto & Campos & Ponderado & Absoluto \\
\hline HAPV & 1 & 3 & SOSR & 1 & 1 \\
SOSR & 2 & 6 & HMNO & 2 & 8 \\
SRIN & 3 & 2 & SESP & 3 & 4 \\
HCRP & 4 & 9 & SCED & 4 & 6 \\
SCED & 5 & 1 & HCRP & 5 & 2 \\
HMNO & 6 & 4 & LMNA & 6 & 5 \\
ELAN & 7 & 5 & SRIN & 7 & 3 \\
SESP & 8 & 8 & ELAN & 8 & 9 \\
LMNA & 9 & 10 & TRTM & 9 & 7 \\
TRTM & 10 & 7 & HAPV & 10 & 10 \\
\hline
\end{tabular}

TABLA 66

Campos referenciales: rangos absoluto y ponderado

\begin{tabular}{|c|c|c|c|c|c|}
\hline \multirow[b]{2}{*}{ Campos } & \multicolumn{2}{|c|}{ Foble wha } & \multirow[b]{2}{*}{ Campos } & \multicolumn{2}{|c|}{ Hobla popular } \\
\hline & Ponderdo & Absolito & & Fonderado & Absoluto \\
\hline SCED & 1 & 5 & SOSR & 1 & 1 \\
\hline SRIN & 2 & 3 & HCRP & 2 & 5 \\
\hline HAPV & 3 & 1 & $S R I N$ & 3 & 7 \\
\hline HMNO & 4 & 6 & $S E S P$ & 4 & 3 \\
\hline$E L A N$ & 5 & 7 & LMNA & 5 & 6 \\
\hline SOSR & 6 & 2 & $S C E D$ & 6 & 4 \\
\hline TRTM & 7 & 10 & TRTM & 7 & 3 \\
\hline SESP & 8 & 8 & HMNO & 8 & 2 \\
\hline$H C R P$ & 9 & 4 & $E L A N$ & 9 & 8 \\
\hline LMNA & 10 & 9 & HAPY & 10 & 10 \\
\hline
\end{tabular}

RA3). Por su parte, en el otro estrato se habla de ocupaciones y servicios (SOSR: RA1), de acciones corporales (HCRP: RA2) y de las relaciones con los demás (SRIN: RA3). En cambio, lo que menos se menciona en el habla culta son los elementos naturales o artificiales (LMNA: RA10), y en el habla popular, lo relativo a atributos psicológicos y valores (HAPV: RA10). Si se considera el rango ponderado (RP) o relativo, lo que más diferencia el habla culta de la popular son los vocablos referidos a atributos psicológicos y valores (HAPV: RP1), los cuales ocupan, en el habla popular, el último rango (HAPV: RP10). 
Por otra parte, si no se consideran las frecuencias sino sólo el número de vocablos (cf. tablas 5 a y 5 b), los campos preponderantes en el habla culta son cultura y educación (SCED: 25 vocablos), relaciones interpersonales (SRIN: 20 vocablos) y atributos psicológicos y valores (HAPV: 14 vocablos). En cambio, en el habla popular los campos con más vocablos fueron ocupaciones y servicios (SOSR: 12 vocablos), relaciones interpersonales (SRIN: 8 vocablos), y elementos naturales y artificiales (LMNA: 8 vocablos).

Es importante señalar, además, que los campos de uno y otro estrato difieren no sólo cuantitativamente, sino también desde el punto de vista del contenido (tabla 4). Para mostrar este aspecto -y considerando lo que antes he descrito-, he intentado, después del análisis, una síntesis. Los dos textos que siguen tienen ese propósito, pero no pretenden mostrar en todos sus matices la temática de los estratos que he estudiado. Deben considerarse sólo como una forma de lustrar algunos de los aspectos del habla culta y popular que se derivan de esta investigación. Para hacerlo me apoyo en los campos más frecuentes y en los vocablos más caracterizadores de cada nno do los estratos, que aparecen en cursivas.

Las personas del nivel culto se preocupan por poder entender las ideas y los puntos de vista. Sienion que deben desarrollar una cultura y una educación. Leer y escribir es para ellos la base que necesitan para esiudiar una carrera en la escuela, para prepararse. Creen además en educar en el hogar con ejemplos. La familia, el padre y la madre, tratan a los hijos con respeto: los cuidan y les cuentan muchas cosas, pero también les exigen en la casa. Juzgan a la gente por sus formas y maneras y les encantan las películas y los deportes.

En el otro nivel, el popular, les interesa el comercio. Compran sobre rodo en el mercado. Allí pagan lo que les venden a voces por kilo. Se levantan temprano durante la semana para agarrar el camión [autobús]. Tal vez los domingos platican con sus compañeros o andan. buscando nowa. Les gusta aydar y preguntar para que los expliquen. Les preocupa que les quiten el agua, y se divierten viendo a los equipos en los campos deportivos durante el campeonato, o cuando alguien del grupo toca algunas canciones por la noche.

\section{Gonclusiones}

En esta investigación he abordado tanto aspectos formales como de contenido del habla culta y popular de la ciudad de México. 
He partido de la suposición de que hay diferencias de los dos tipos entre los dos estratos. Esa suposición se confirmó con los resultados. En efecto, el habla culta tiene enunciados más largos, es más densa y utiliza más vocablos que el habla popular.

En cuanto al contenido, hay una diferencia muy significativa en el empleo de vocablos con referentes no perceptibles, que fueron más frecuentes en el habla culta. Por otra parte, en el habla popular predominan unos campos referenciales y otros en el habla culta. Además, los vocablos que utilizan uno y otro estrato en los mismos campos son también distintos. Esto se refuerza por el hecho de que en el habla culta los conceptos no perceptibles se concentran en cultura y educación (SCED), relaciones interpersonales (SRIN) y atributos psicológicos (HAPV) - los tres campos más frecuentes desde el punto de vista de su rango absoluto. En cambio, en el habla popular no se aprecia una concentración, sino más bien una dispersión de ese tipo de referentes en diferentes campos.

Los resultados permiten señalar algunas semejanzas en rehación con los que obtuve on mis investigaciones anteriores. En la muestra de nivel nacional que estudié previnmente, los conceptos de tipo no perceptible fueron claramente más frecuentes, en las dos clases de palabras, en el estrato alto ${ }^{28}$. En cuanto al léxico, los campos predominantes en el mismo estrato fueron muy parecidos a los que ahora encontré29.

En cambio, en el habla popular hay diferencias significativas en relación con la importancia de los campos referenciales con respecto a mis resultados para la ciudad de México. En el nivel nacional los campos más caracterizadores de las diferencias entre los dos estratos fueron alimentos y cultura y educación, que ocuparon, respectivamente, el primero y el úlimo rango en el habla popular. Por otra parte, cultura y educación ocupó el primer rango en el habla culta, y alimentos el ultimo (Ávila 1991, p. 314 , y Ávila 1993).

Las diferencias podrian explicarse por el hecho de que en la muestra nacional se incluyeron, en el estrato bajo, personas - - so-

28 Cf., para los sustantivos, Ávila 1991; y para los verbos Ávila 1993.

29 En los sustantivos de la muestra nacional que analicé previamente (Ávila 1991, p. 313), los campos de los primeros cuatro rangos del nivel alto fueron culura y educación, servicios, atributos psicológicos y relaciones inter personales. En cuanto a los verbos (ÁvLA 1993), los campos más frecuentes fueron atributos psicológicos, cultura y educación, y relaciones interpersonales. 
bre todo campesinos ${ }^{30}$ - con importantes carencias económicas y de otros tipos - lo que explica su emigración a las ciudades. Ellos hablaron de sus necesidades básicas, mientras que en el estrato alto, ya superadas esas necesidades, se habló más frecuentemente de educación y cultura.

Evidentemente la situación no es la misma en la capital del país. Por eso en la ciudad de México las referencias a alimentos no fueron significativas en ninguno de los dos estratos. En cambio, sí hubo diferencias en el campo de la cultura y la educación, pero no tan marcadas como las que encontré en la muestra nacional.

Es natural que las personas hablen de temas que les importan de acuerdo con su condición social, su trabajo, sus ingresos y sus intereses ${ }^{31}$. Aunque se discutan las relaciones entre lenguaje y grupo social, no parece haber discrepancias en lo relativo a las diferencias entre el lenguaje de estratos sociales diferentes (Kress \& Hodge 1975, p. 65) ${ }^{32}$. Esto explica el hecho de que - dentro de los términos que he empleado en esta investigación - se utilicen carroos referenciales diferentes, tonto cuaritativa cono cualita. tivamente, en grupos socides distintos. Wr consecuencia. las diferencias sociosemánticas deben ser mayores contorme sea mayor la desigualdad social: se encontrarán más entre un obrero y un intelectual si son mexicanos que si son franceses (cf. Bourdieu 1979), pero en uno y otro caso existen. En ese mismo sentido, se puede decir que un intelectual y un banquero, aunque utilicen las mismas formas lingüísticas, son necesariamente diferentes en el contenido de sus discursos ${ }^{33}$.

${ }^{30}$ En la muestra nacional es frecuente el léxico rural. Las entrevistas -hechas para el ALEM (1990)-- buscaban precisamente diferencias léxicas entre las zonas. Estas diferencias aparecen sobre todo en los hablantes con menor nivel de instrucción. Por otra parte, el léxico que recogí se asemeja al que podria encontrarse en el diccionario de una lengua indigena americana. según observó $T$. Smith. Esto sugiere que, en cuanto al vocabulario, la visión de esas lenguas está condicionada por el ambiente y el tipo de relaciones económicas y de trabajo.

31 He comentado esto antes (Ávila 1991, p. 280). Cf. asimismo GuY 1988, p. 37.

32 Para esos investigadores, "the only question to decide concerns the function of these differences and their role in a total economic and social order" (KREsS \& HODGE 1979, p. 65).

33 Como dice Lavandera 1984, pp. 15-16, "el miedo a hacer afirmaciones que pongan en duda la "igualdad» lingüística, cultural y cogniciva de todos los seres humanos" ha conducido a algunos sociolingüistas - continúa- 
Sin embargo, el hecho de que los estratos sociales hablen de manera diferente tanto desde el punto de vista de la forma como del contenido, no implica que uno de los discursos sea mejor que el otro. Labov $(1972$, p. 179) ha señalado la grandilocuencia de la clase media, su tendencia a matizar en exceso y su frecuente actitud de buscar status mediante recursos lingüísticos, lo que a veces produce discursos vacios o dificiles de comprender. También se ha discutido la idea de Bernstein de que el estrato menos privilegiado tiene dificultades para generalizar o abstraer ${ }^{34}$.

Frente a esto, se puede decir que en el habla popular sí se utiliza el léxico abstracto en forma activa - y pasivamente sin duda se comprenden más vocablos-, aunque con menos frecuencia que en el habla culta. Es cierto que hay una diferencia, condicionada socialmente, en el sentido de que un estrato utiliza más ese tipo de léxico, pero diferencia no significa deficiencia. Todo grupo social es diferente, y se define por sus diferencias, a veces dificiles de precisar. Y así como el que tiene más riqueza económica no necesariamente se alimentará bien si no sabe dietética, quien tene un mayor vocabulario no necesariamente va a ser más ef. ciente en la comunicación.

En todo caso, lo importante es destacar que la sociedad y la escuela se han interesado más por los síntomas - las diferencias de forma que todos perciben- y menos por los símbolos - que son más difíciles de ubicar ${ }^{35}$. Lo que importa es cambiar de actitud para valorar más los símbolos y preocuparse menos por los síntomas.

Raúl Ávila

El Colegio de México

a "rechazar la posibilidad. . de que distintos grupos sociales o distintas situaciones tengan necesidades y propósitos diferentes en cuanto al tipo de mensajes que se intercambian, y por lo tanto, esas diferencias condicionen la elección de los significados que permiten transmitir tales mensajes".

34 De acuerdo con BERNSTEIN 1971 el código restringido - más frecuente en los estratos bajos que en los medios- supone limitaciones en las posibilidades de generalizar y de abstraer. Véase al respecto la discusión que aparece en KRESS \& HODGES 1979, pp. 67-68. Sobre la idea del estereotipo de una clase social y sus peligros, cf. HaLLiDAY 1978, p. 23. Véanse asimismo mis propios argumentos al respecto en Ávila 1985, pp. 345 ss.

${ }^{35} \mathrm{La}$ sociedad aprueba un tipo de lenguaje que llama "correcto" porque corresponde al uso de los grupos prestigiosos, y rechaza toda norma divergente. Sin embargo, esa aprobación - reitero, con Bourdieu - se sustenta fundamentalmente en las diferencias formales, más que en las de contenido (c. Bourdieu 1990, p. 127). 


\section{BIBLIOGRAFÍA}

ALEM 1990. Atlas lingüistico de México. T. 1: Fonética. Dirigido por Juan M. Lope Blanch. El Colegio de México-F.C.E, México.

Albert, E. M. 1972. "Culture patterning of speech behavior in Burundi", en Gumperz \& Hymes 1972. Pp. 72-105.

ÁvILA, R. 1985. "La langue espagnole et son enseignement: oppresseurs et opprimés", en La crise des langues. Ed. J. Maurais. Conseil de la Langue Française-Le Robert, Québec-Paris, pp. 331-364.

- 1988a. "Análisis de textos escritos en población escolar mexicana", en Lenguaje oral y escrito. Eds. A. Ardila y $F$. Ostrosky-Solis, Trillas, México, pp. 194.206

_ 1988b. "Lengua hablada y estrato social: un acercamiento lexicoestadistico", NRFH, 36, 131-148.

— 1991. "Sobre semántica social: conceptos y estratos en el español de México", Estudios Sociológicos (El Colegio de México), 9, 279-314.

— 1993. "Sociosemántica: referentes verbales en el español de Mćxico", ponencia presentada en el X Congreso ALFAL, Veracruz, Ver, México, 11

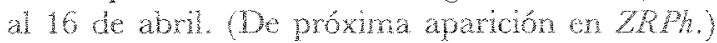

BaLdinger, K. 1967. "Structures et systèmes linguistiques", ThL, 1, 123-139.

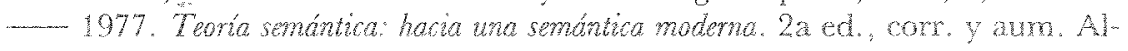
calá, Madrid.

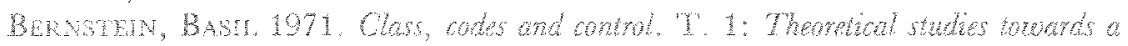
sociology of language. Routedge \& Kegan Raul, London.

Bourdieu, Pierre 1979. La distinction. Eds. du Minuit, Paris.

- 1990. Sociología y cuitura. CONACULTA-Grijalbo, México.

Bunler, Karl 1967. Teoría del lenguaje. Rev. de Occidente, Madrid.

Casares, Julio 1959. Diccionario ideológico de la lengua española. 2a. ed. G. Gili, Barcelona.

Coseriu, E. 1964. "Pour une sémantique diachronique structurale", TLL, 1, 139-186.

DEM 1986. Diccionario básico del español de México. Dirigido por L. F. Lara. El Colegio de México, México.

Dornsetre, Franz 1970. Der deutsche Wortschaiz nach Sachgruppen. 7a. ed. Walter de Gruyter, Berlin [1a. ed.: 1933].

DRAE 1992. Real Academia Española, Diccionario de í lengua espuñola. 21 ed. Real Acadenia Española, Madrid.

DuTCh, ROBERT A. 1962. Roget's Thesauras of English words and phrases. New ed. rev. and modemized by... Longmans Green, London.

Exegesis 1992. R. ÁvilA (diseño) e IBM (programación), Exegesis (programa de cómputo). El Colegio de México e TBM de México.

GuMPerz, JOHN J., \& DeLi HYMes (eds.) 1972. Directions in sociolinguistics. The thrography of communication. Holt, Rinehart \& Winston, New York.

GuY, G. R. 1988. "Language as social class", en NewMEYer 1988. Pp. 37-63.

Habla culta 1971. El habla [culta] de la ciudad de México. Materiales para su estudio. UNAM, México (Pubis. del Centro de Lingüistica Hispánica, 3).

Habla popular 1976. El habla popular de la ciudad de México. Materiales para su esiudio. UNAM, México (Publs. del Centra de Lingüistica Hispánica, 4). 
HAllDAY, M. A. K. 1970. "Language structure and language function", en Neze horizons in linguistics. Ed. J. Lyons. Penguin, Middlesex, pp. 140-165. 1978. Language as social semiotics. Edward Arnold, London.

HALIIX, R., \& W. VON WARTBURG 1963. Begriffssystem als Grundlage für die Lexikographie $=$ Système raisonné des concepts pour servir de base à la lexicographie. Essay d'un schéma de classement. 2e. éd. recomposée et augmentée. Akademie Verlag, Berlin [1a. ed.: 1952].

HWGR, K. 1965. "Les bases méthodologiques de l'onomasiologie et du classement par concepts", TLL, 1, 7-32.

Hymrs, D. 1972. "Models of interaction of language and social life", en GUMperz \& HYMies 1972. Pp. 35-71.

-1-1974. "Hacia etrografias de la comunicación", en Antologia de estudios de etnolingüística y sociolingüistica. Eds. P. Garvin y Y. Lastra. UNAM, México, pp. $48-89$.

JAKOBSON, R. 1963. "Linguistique et poétique", Essais de linguistique générale. Trad. N. Ruwet. Éds. du Minuit, Paris.

KI.ARH, G. R. 1978. "Assessing readability", en Reading from process to practice. Eds. L. J. Chapman \& P. Gzemiewska. London.

KRess, G., \& R. Hopoe 1979. Language as idoology. Rouledge \& Kegan Paul, London.

LABow. W. 1972. "The loge of non-standard English", on Langugge and social

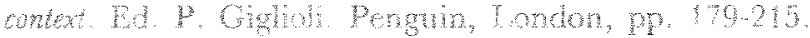

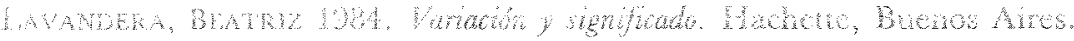

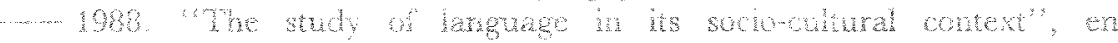
Newminer 1988. Pp. $1-13$

Molmer, Maria 1983. Diccionario de uso del español. 2 ts. Gredos, Madrid.

Newmeyse, Frephrick J. (ed.) 1988. Linguistics: The Cambridge survey. T. 4: Language: The socio-cultural context. Cambridge University Press, Cambridge.

PotTier, B. 1965. "La définition sémantique dans les dictionnaires", TLL, 1, 33-39.

STERn, C. 1990. "Notas para la delimitación de las clases medias en México", en Las clases medias en la coyuntura actual. Comps. S. Loeza y C. Stern. El Colegio de México. México. pp. 19-27.

Walters, K. 1988. "Dialectology", en Newmeyer 1988. Pp. 119-139.

\section{ANEXO}

HABLA CUITA: SUSTANTINOS

umbiente fo 22 fp 04 ft 26 df 18 dr\% C450 ra CS12 acepciones

CP Medio social, entorno, circunstancia.

contextos

habla culta: "La mujer se puede desarrollar en otro ambiente distinto".

habla popular: "[Si uno va solo] se hace más ambiente, que "yend'" uno [yendo unol con sus papás".

Sí/ No Perceptible np campo referencial WLAN 
$\begin{array}{llllllll}\text { amor } & \text { fc } 11 & \text { fp } 04 & \text { ft } 15 & \text { df } 07 & \text { df\% } & \text { C175 } & \text { rn CS30 }\end{array}$

acepciones

CP Sentimiento, afecto.

contextos

habla culta: "Necesitamos dar amor y que se nos dé".

habla popular: "¿Quién es Enedina? ¡Tu grande [sic] amor!"

Sí / No Perceptible NP campo referencial HAPV

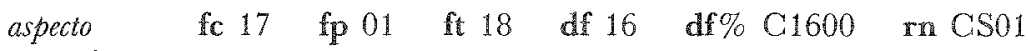

acepciones

CP Sentido, apariencia, tópico.

contextos

habla culta: "Ya está en la edad en que empieza a despertar en ese aspecio". habla popular: "Yo tuve la culpa en ese aspecto".

Sí / No Perceptible NP campo referencial SCED

$\begin{array}{llllllll}\text { base } & \text { fc } 20 & \text { fp } 06 & \text { ft } 26 & \text { df } 14 & \text { df } \% & \text { C233 } & \text { rn CS20 }\end{array}$

acepciones

CP Fundamento.

contextos

habla culta: "Gente más o menos educada y con unas bases morales bastante firmes"

habla popular: "La hose principal es el dinero".

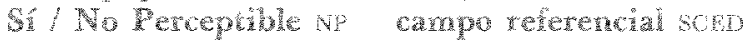

caballo fe 17 fp 00 fit 17 df 17 df $\%$ C100+ $\operatorname{mr}$ CS38

acepciones

c Corcel.

contextos

habla culta: "Y además el caballo sabía ver los semáforos".

Sí / No Perceptible SP- campo referencial LMNA

$\begin{array}{llllllll}\text { carera fe } 31 & \text { fp } 13 & \text { ft } 44 & \text { df } 18 & \text { df } \% \text { C138 } & \text { min CS33 }\end{array}$

acepciones

CP Ciclo de estudios.

contextos

habla culta: "En primero y segundo, tuve que dejar deportes, tuve que dejar todo, y dedicarme exclusivamenta a la carrera".

habla popular. "Bucno, si no tengo dinero para sostenerio más, otra cancra más, "pos" no, no se puede".

Sí / No Perceptible NP campo referencial SCED

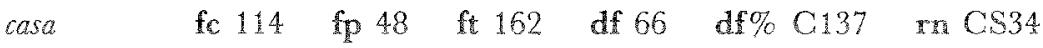

acepciones

GP Vivienda.

contextos

habla culta: "Todo dentro de su casa: no salen, no conocen la banqueta". habla popuiar: "Mi mamá, en primera, como siempre ella ha trabajado, pues nunca ha estado [mucho tiempo] en la casa". 


\section{Sí / No Perceptible sP campo referencial ELAN}

caso $\quad$ fc $31 \quad$ fp $11 \quad$ ft 42 df 20 df $\%$ C181 $\quad$ rn CS27

acepciones

CP Circunstancia, situación.

contextos

habla culta: "Tambien [hace falta] cierta cultura para poder actuar en un caso previsto".

habla popular: "Su caso de este niño es especial. Entonces, "usté» va tener que hablar con el director para que le dé una prórroga".

Sí / No Perceptible NP campo referencial SCED

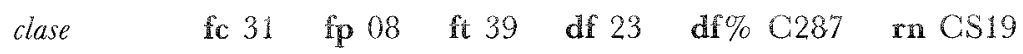

\section{acepciones}

C Enseñanza escolar; p Tipo, calidad.

contextos

habla culta: "No puedo darte tiempo para que te vayas todo el día, en la mañana, a recibir tus clases en la [escuelal preparatoria [preuniversitaria]". habla popular: "Venden toda clase de comidas, principalmente yucatecas". Si / No Perceptible NP campo referencial SCED

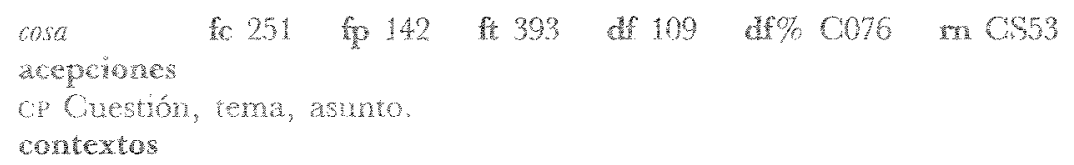
cimos en la escuela".

Sí / No Perceptible NP campo referencial SCED

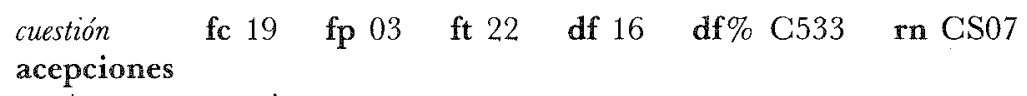

habla popular: "En cuestion de ropa o alguna cosa, pues lo compran «pa" todos".

Sí / No Perceptible NP campo referencial SCED

culumat fe 40 fp 00 ft 40 af 40 af\% $\mathrm{C} 100+$ m CS38

acepciones

c Conocimiento, sabiduría.

contextos

habla culta: "Pero no tienen una cultura, propiamente, una visión amplia". Sí / No Perceptible NP campo referencial SCED

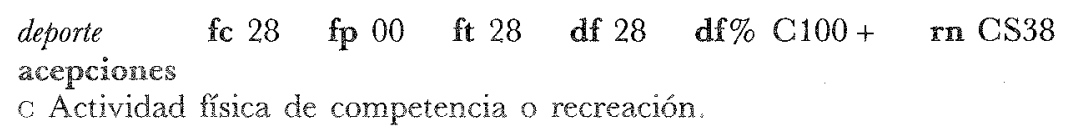




\section{contextos}

habla culta: "El deporte que él quiera o que piense desarrollar, que lo desarrolle, y como una distracción".

Si / No Perceptible SP campo referencial SESP

derecho fo 13 rpo6 ft 19 dro7 df\% C116 ru CS36

acepciones

cP Facultad y libertad de hacer o exigir algo.

contextos

habla culta: "La mujer, cuando lleva dinero a su casa, se siente con derecho a exigir y a ordenar".

habla pormar: "Ya no va a tener dereho a. . a seguro social".

Si / No Perceptible NP campo referencial HAPV

edad fc 22 fp 12 ft 34 df 10 df\% C083 rm CS51

acepciones

CP Tiempo que se ha vivido.

contextos

habla culta: "Pero de chamacos [chicos, nimos". digamos hasta la odud de doce años, una cosa así, lo tomábamos como diversión".

habla popular: "Le digo yo que me vine a la adad de trece años con una tía".

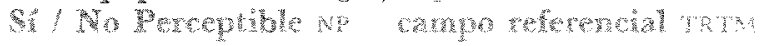

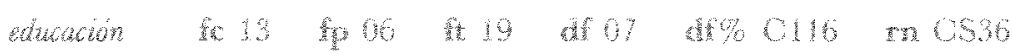

acepciones

CP Formación, instrucción.

contextos

habla culta: "Porque no va con su manera de ser: porque no va con su educación".

habla popular: "Si tiene uno hijos, [es necesario] sobrellevarse, darles una educación bien".

Sí / No Perceptible NP campo referencial SCED

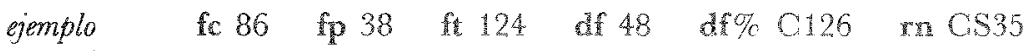

acepriones

CP Hecho representativo o ininable.

contextos

habla culta: "El ejomplo de la casa simmpre se ve"

hablat popular: "¿I qué sientes, digo, al componer una cancion? por genplo, esa que acabamos de mencionar".

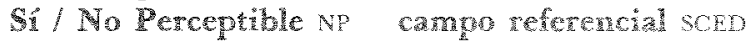

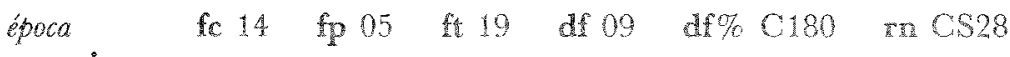

acepciones

op Etapa, temporada.

contextos

habla cula: "Decía que era la mejor éfoca de su vida".

habla popinax: "Te dié que en aquella época las personas eran bien "superti. ciosass". 
Si / No Perceptible NP campo referencial TRTM

\section{escuela fo $34 \quad$ fp 22 ft 56 df 12 dr\% C054 m CS54}

acepciones

cP Centro de enseñanza, institución.

\section{contextos}

habla culta: "No la mandaron a la escuela porque estaba mal visto".

habla popular: "Se paran a la carrera, nomás lavándose, y se van a la escuela, a veces, sin desayunar y nada".

Sí / No Perceptible SP campo referencial SCED ELAN

falta fe 18 fpo4 fit 22 de 14 dr\% C350 m CS13

acepciones

CP Hecho de no haber algo que se desea.

contextos

habla culta: "Lo que antes era disciplina por miedo, se vuelve indisciplina y al tú por tú: la falia de respeto total hacia el padre".

habla popular: "Es por falta de... dinero".

Sis / No Perceptible NP campo referencial sRM

familia fo 41 fp 10 ft 51 df 31 de C 310 m CS17

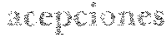

cre Grupo social baston.

conderestos

habla culta: "No es posible estar trayendo a la famita cono gitanos de un lugar a otro".

Wabla popular: "Le digo a "usté» que depende [de] la familua".

Sí/ No Perceptible SP campo referencial SRIN

forma fe $24 \quad$ fp 09 ft 33 df 15 df\% C166 rn $\quad$ CS32

acepciones

CP Modo, manera de tratar a alguien o hacer algo.

contextos

habla culta: "Nos educaron en una forme demasiado idealista: de no mentin".

labia pepular. "Es que eteng" wa foma de contestar, que dicen que muchas veces la toman a mal".

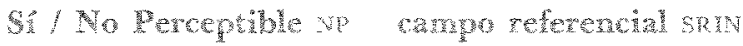

Sgente fo 95 fp 55 ft 130 af 60 dfo C17l m Cs31

aceperiones

cr Conjunto de personas.

contextos

habla culta: "Bueno, pero qué curioso, que a la gente lo que le dio por ponerle sean collares".

habla popular: "Oiga: y aquí la gente es muy unida, ¿no?"

Si / No Perceptible SP campo referencial SRIN

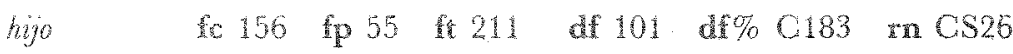


acepciones

CP Vástago.

contextos

habla culta: "Y el padre debe cuidar su vida para el hijo".

habla popular: "Y el hijo que está soltero se irá, y el casado "pus" yo "creó" se queda".

Sí / No Perceptible sP campo referencial SRIN

$\begin{array}{llllllll}\text { hogar fo } 63 & \text { fp } 10 & \text { ft } 73 & \text { df } 53 & \text { df\% } & \text { C530 } & \text { m CS08 }\end{array}$

acepciones

CP Familia y morada.

contextos

habla culta: "Me encanta mi casa y me encanta mi hogar".

habla popular: "Pero a la vez piensas en tu familia, en tu hogar".

Sí / No Perceptible NP campo referencial SCED SRIN

hombre fc 146 fp 33 ft 179 df 113 df\% C342 rn CS15

acepciones

$\mathrm{CP}$ Persona de sexo masculino.

contextos

habla culta: "Tú ves la injusticia, luego, del hombre, de tener siempre sujeta a in muire"

halda popaln: "Ya se le caso un hombe y una mujer".

Si: No Perceptivies campo refereacial hivo

idea fo 17 fp 00 ft 17 df $17 \mathrm{df} \% \mathrm{Cl00}+\mathrm{rnCS} 38$

acepciones

c Concepto, noción

contextos

habla culta: "Digo, ésa es la idea que tenemos nosotros".

Sí / No Perceptible NP campo referencial HAPV

iglesia fe $22 \quad \mathrm{fp} 07$ ft 29 df 15 dro C214 in CS22

acepciones

CP Templo.

contextos

habla culta: "Vaya a la iglesia, platíquele esto a Dios, piénselo, sea usted un poco más sufrida".

habla popular: "Ya ve que en muchas iglesias hay órganos".

Sí / No Perceptible sP campo referencial SCED ELAN

interés fo 18 fp 02 fit 20 df 16 df\% C800 m CS05

acepciones

CP Inclinación, gusto.

contextos

habla culta: "No tuve ningún medio ambiente que me favoreciera a tener interés de estudiar".

habia popular: "Quizá tendría interés en él, yo me imagino eso".

Sí / No Perceptible NP campo referencial HAPV 
CP Sitio.

\section{contextos}

habla culta: "La gente preparada se va a buscar otro empleo en otro lugar". habla popular: "Me gusta demasiado el lugar, el ambiente, las personas que vienen aquî".

Sí / No Perceptible NP campo referencial ELAN

\section{madre fe $27 \quad$ fp 03 ft 30 df 24 df\% $\quad$ C800 $\quad$ rn CS05}

acepciones

cP Mujer que ha tenido un hijo.

contextos

habla culta: "No puede haber unidad, porque no se puede dedicar ni la madre ni el padre a ellos [a los hijos]".

habla popular: "[Preguntaron] que si estábamos todos los padres y las madres de acuerdo en que les dieran todas esas clases".

Si / No Perceptible SP campo referencial SRIN

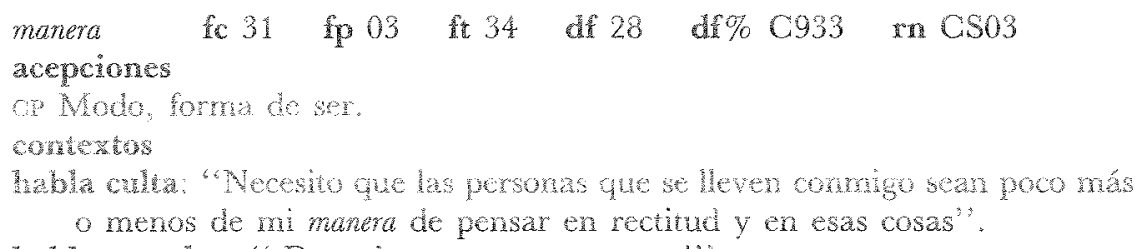


Sí / No Perceptible NP campo referencial SRIN

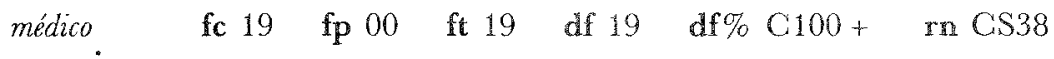

acepciones

c Persona que ejerce la medicina.

contextos

habla culta: "Yo le aconsejaría que fuera a ver usted a un médico".

Sí / No Perceptible SP campo referencial SOSR

momento fe 21 fp 11 fft 32 df 10 df\% C090 $\operatorname{maS}$ CSO

acepciones

cp Instante.

contextos

habla culta: "Oigame un momento: a mí se me presentó un problema y no fue así..."

habla popular: "Fijese que llega un momento en [que] uno se fastidia".

Sí / No Perceptible NP campo referencial TRTM

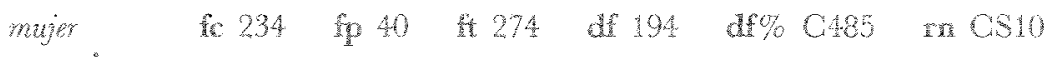

acepciones

CP Persona adulta de sexo femenino.

ortextos

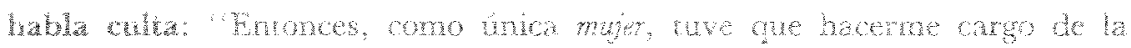
cases".

habla popular: "Quién se va a poner con una mujer?"

Si / No Perceptible Sp campo referencial HMNO

$\begin{array}{llllllll}\begin{array}{l}\text { mundo fo } \\ \text { acepciones }\end{array} & \text { fc } 28 & \text { fp } 03 & \text { ft } 31 & \text { df } 25 & \text { df } \% \text { C833 } & \text { m CSO4 }\end{array}$

CP Conjunto de personas.

contextos

habla culta: "Las de ahora se dedican a sacar a todo mundo en bikini".

habla popular: "Todo el mundo me han [sic] dicho así".

Sí / No Perceptible NP campo referencial SRIN

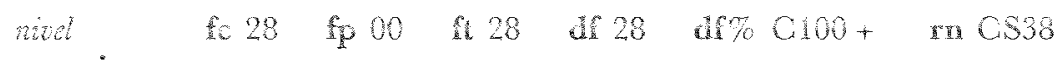

acepciones

c Grado de una cualidad.

constextos

habla culta: "El nivel de la cultura del oficial mexicano, ya es muy difercnte". S1/ No Perceptible Np campo referencial sced

obra fe 17 fpo0 ft 17 df 17 df\% C100+ m CS 38

acepciones

c Producto, sobre todo cultural.

contextos

habla culta: "Tuve que irme a la... al diccionario, estudiar varias obras, consultar, preguntar, pedir orientación por todos lados".

Sí/ No Perceptible SP campo referencial SCED 
$\begin{array}{llllllll}\text { ocasión } & \text { fc } 14 & \text { fp } 05 & \text { ft } 19 & \text { df } 09 & \text { df } \% & \text { C180 } & \text { rn CS28 }\end{array}$ acepciones

cP Circunstancia, vez, oportunidad.

contextos

habla culta: "Ya había habido como tres o cuatro ocasiones que había pasado to mismo".

habla popular: "He ido dos ocasiones".

Sí / No Perceptible NP campo referencial TRTM

$\begin{array}{llllllll}\text { padre } & \text { fc } 63 & \text { fp } 16 & \text { ft } 79 & \text { df } 47 & \text { df\% } & \text { C293 } & \text { rn CS18 }\end{array}$

acepciones

cp Progenitor.

contextos

habla culta: "Debemos todos los matrimonios marchar de común acuerdo, a padre y la madre, para tomar las decisionies, para cómo edncar a wn hijo".

habla popular. " "Ora" [ahora] verás con tu padre: le voy a decir cómo me estás diciendo!"

Sí / No Perceptible SP campo referencial SRIN

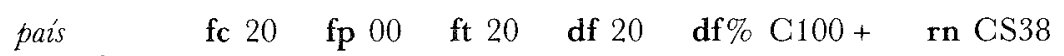

acepciones

c Unidad política constituida en un territorio.

contextos

habla culta: "Es un pais en que tiene apenas una generación y media en que la mujer está trabajando".

Sí / No Perceptible NP campo referencial ELAN SCED

pelicula fe 30 fp 00 ft 30 df 30 df\% C100+ in CS38

acepciones

c. Fime.

contextos

habla culta: "Es una película preciosa".

Sí / No Perceptible sł campo referencial sesp

plan fo 13 fp 04 ft 17 df 09 df $\%$ C225 rn CS21

acepciones

CP Proyecto.

contextos

habla culta: "Yo lo estoy dejando nada más en el plan de desarrollo intelectual de la mujer".

habla popular: "Es que, cuando se hacen planes, se derrumba todo".

Sí / No Perceptible NP campo referencial SCED

$\begin{array}{llllllll}\text { problema } & \text { fc } 53 & \text { fp } 18 & \text { ft } 71 & \text { df } 35 & \text { df } \% & \text { C194 } & \text { rn CS25 }\end{array}$

acepciones

CP Dificultad, complicación.

contextos

habla culta: "Todo eso es perfecto, pero ve al fondo del problema". 
habla popular: "Por eso tenemos el problema de que queremos saber si nos venden o no".

Sí / No Perceptible NP campo referencial SCED

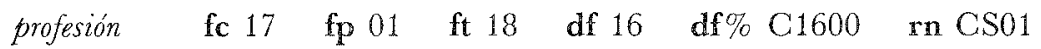

acepciones

CP Oficio que requiere estudios.

contextos

habla culta: "Hay, por ejemplo, amistades de mi marido que tengo que tratar a fuerza ¿no?, por su profesión".

habla popular: "Tú tienes tu trabajo y lo tuyo en la guitarra. Porque también puede ser una profesión".

Si / No Perceptible NP campo referencial SOSR

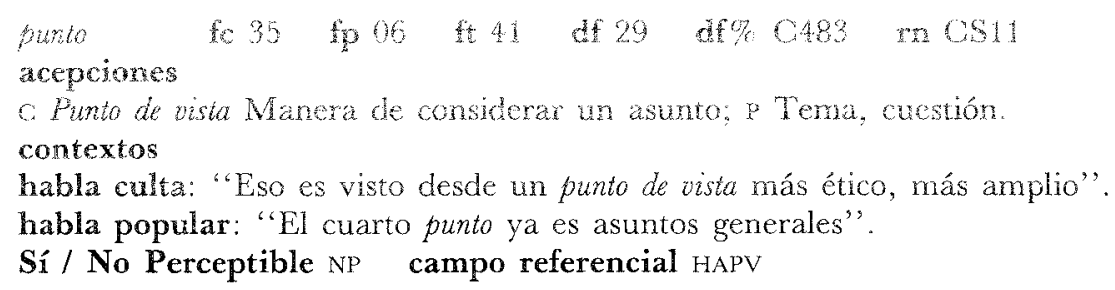




\section{contextos}

habla culta: "Son teorías, si tú quieres, de tipo socialista".

habla popular: "Y para ti, ¿qué es lo que más [le ... ] gusta a la gente? ¿Bolero, ranchero o... o qué tipo de [música]?"

Sí/ No Perceptible NP campo referencial SCED

vida $\quad$ fc $77 \quad$ fp $26 \quad$ ft 103 df $51 \quad$ df\% C196 $\quad$ rn CS24

acepciones

CP Existencia temporal y ambiente en la que ocurre.

contextos

habla culta: "Decía que era la mejor época de su vida, nada más que había perdido el tren porque no hacía cuentas".

habla popular: "La jida en provincia es más sencilla, pero es más barata". Si / No Perceptible NP campo referencial ELAN

\section{ANFXO 2}

Habia CULTA: VERBOS

$\begin{array}{llllllll}\text { acordarse } & \text { fc } 57 & \mathbf{f p} 06 & \mathbf{f t} 63 & \text { df } 51 & \text { df\% } & \text { C850 } & \text { rn CV04 }\end{array}$

acepciones

CP Recordar.

\section{contextos}

habla culta: "No te acuerdas de Cutberto? Uno que tocaba el piano, muy malo".

habla popular: "Todo el tiempo se está acordando de él".

Sï/ No Perceptible NP campo referencial HAPV

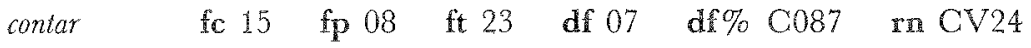

acepciones

c. Narrar, relatar; $\mathrm{P}$ Considerar, tomar en cuenta.

contextos

habla culta: "Qué chistoso nos contó sus peripecias que le habían pasado!" habla popular: "Los aplausos son los que cuentan, ¿no?"

Sí / No Perceptible NP campo referencial SCED

$\begin{array}{llllllll}\text { creer fe } 155 & \text { fp } 72 & \text { ft } 227 & \text { df } 83 & \text { df\% } & \text { C115 } & \text { rn CV17 }\end{array}$

acepciones

$\mathrm{CP}$ Suponer, persar.

contextos

habla culta: "Creo que es una ventaja tremenda la educación mixta".

habla popular: "Pero creo que me costó más trabajo ver a ustedes que al presidente".

Si / No Perceptible NP campo referencial HAPV

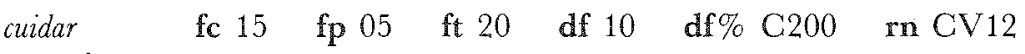

acepciones

CP Dar cuidados, atender. 


\section{contextos}

habla culta: "Contéstame esto, ¿quién debe cuidar los hijos: el marido o la mujer?"

habla popular: "No, «pus" de... andar cuidando los animales en el rancho", Si / No Perceptible NP campo referencial SRIN

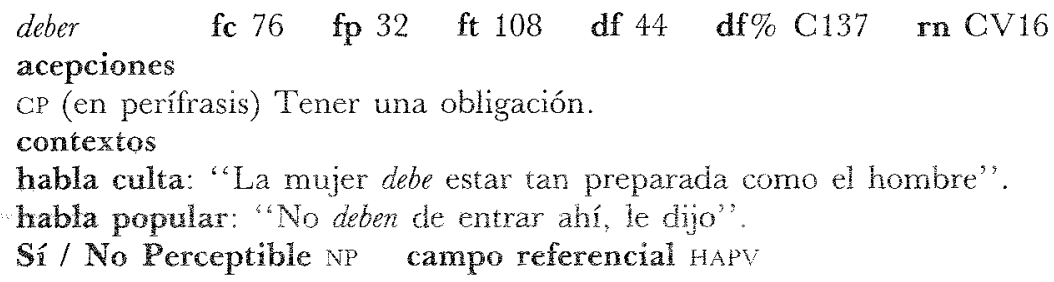

habla culta: "Nosotros debemos de desarrollar una posición, un nivel".

habla popula: "Entonces, la primera vez que se le desamolló las amigdalitis [sic], este... "l" [le] entro fiebre".

Sí / No Perceptible NP campo referencial SCED

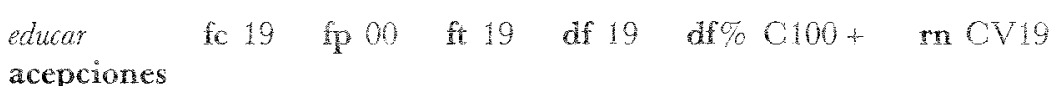

c Dar educación o instrucción.

contextos

habla culta: "Si tienes ideas diferentes desde un principio, no puedes educar a tus hijos".

Si / No Perceptible NP campo referencial SCED

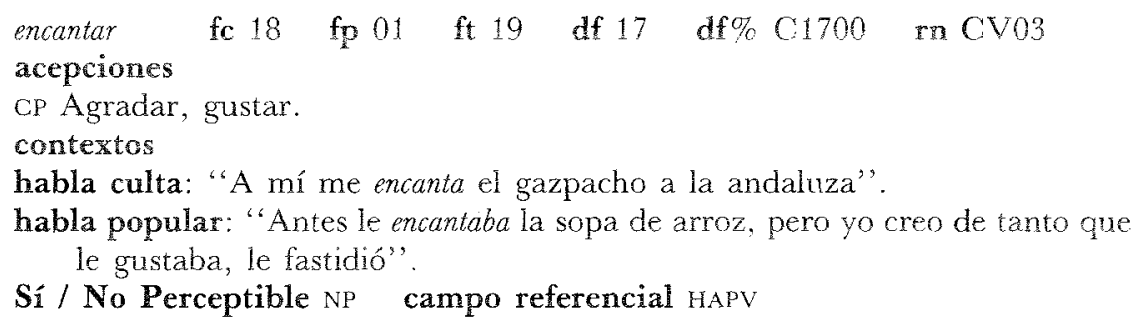




\section{acepciones}

cP Hallar algo o a alguien.

contextos

habla culta: "[E]] buen ejernplo, los consejos, la ternura, el respeto... [los] encuentran en la casa".

habla popular: "Y donde vaya..., ¿yo voy a encomirar trabajo?"

Si / No Perceptible NP campo referencial SRIN

\section{eniender fo 22 fp 04 f 26 df 18 dr\% C450 m aV07}

acepciones

cp Comprender.

contestos

habla cultra: "Están los que entienden la mente de los hombres, ¿no?"

habla popular: "No se le entiende a ese doctor: primero que no coma; luego

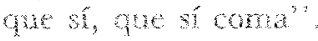

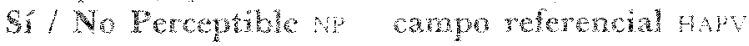

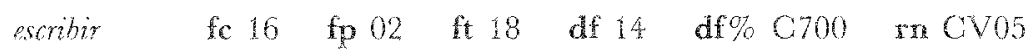

acepciones

CP Redactar.

contextos

habla culta: "Quemé mis cartas que yo le escribi a Manuel, porque él las tenía todas archivadas, tú, en un portafolio".

habla popular: "Bastante hacía el chamaco con saber leer y escribir".

Sí / No Perceptible SP campo referencial SCED

estudiar fc 55 fp 33 ft 88 df 22 df\% C066 m CV26

acepciones

CP Aprender, rener estudios.

contextos

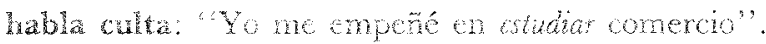

habla popular: "Fos" yo estudié... "uora" si que [para] andar picandole la cola a los bueyes en mi tiema!"

Si / No Perceptible N ampo referencial seeD

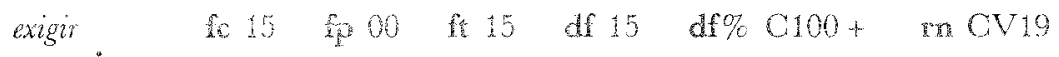

acepciones

c Demandar, hacer una exigencia.

contextos

habla culta: "A quién le puedes exigir que las cosas estén listas, si la persona a la que lo tienes que exigir no está?"

Sí / No Perceptible NP campo referencial SRIN

juzgar fc 17 fp 00 ft 17 df 17 df $\%$ C $100+$ rn CV 19

acepciones

c Enjuiciar, opinar.

contextos

habla culta: "No puedes juzgar a la mujer por el hecho de estar en su casa". Si / No Perceptible NP campo referencial HAPV 
$\begin{array}{llllllll}\text { leer fe } 16 & \text { fp } 06 & \text { ft } 22 & \text { df } 10 & \text { df } \% & \text { C166 } & \text { rn CV13 }\end{array}$

acepciones

CP Comprender lo escrito.

contextos

habla culta: "Si acaso, leen el periódico de sociales".

habla popular: "Por eso prefiero llegar a mi casita, «m'» encierro y me pongo a leer el periódico".

Sí / No Perceptible sp campo referencial sced

morir $\quad$ fc 32 fp 12 ft 44 df 20 df\% Ci66 rm CV13

acepciones

CP Fallecer:

contextos

habla culta: "Un torero que se muere en el ruedo... se consagra".

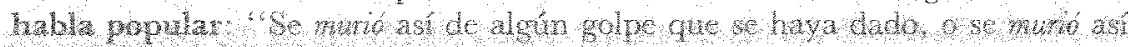
de la muerte natural'".

\$1/ No Perceptible sP campo referencial HCRP

$\begin{array}{llllllll}\text { nacer fe } 16 & \text { fp } 03 & \text { ft } 19 & \text { df } 13 & \text { dro } & \text { C } 433 & \text { m CV08 }\end{array}$

acepciones

CP Empezar a vivir.

contextos

habla culta: "Y no es cierto: mi hija tiene ese interés, porque nació con ese interés".

habla popular: "Ahí vivíamos. Ahí nació uno de mis niños".

Sí / No Perceptible SP campo referencial HCRP

necesitar fe 43 fp 22 ft 65 df 21 df\% C095 rn CV23

acepciones

CP Requerir algo de alguien.

contextos

habla culta: "Porque dentro de la milicia se ve que necesitan abogados".

habla popular: "Eres medio parco para hablar. Te necesito sacar las palabras con tirabuzón".

Sí / No Perceptible NP campo referencial SRIN

oir ffe 61 fp 31 ft 92 df 30 df\% C096 rn CV22

acepciones

CP (vocativo) Demandar atención.

contextos

habla culta: "Oye, Nena, ¿sabes lo que pasó?"

habla popular: "Pero él toma primero la conversación, oiga!"

Sí / No Perceptible SP campo referencial SRIN HCRP

poder fc 289 fp 140 ft 429 df 149 df\% C106 rn CV18

acepciones

CP Tener capacidad para hacer, lograr algo.

contextos 
habla culta: "Es lo que hace falta para poder llevar una maestría o un doctorado"

habla popular: "Este... «hablanos" [hablarnos] unos a los otros para que todos nos podamos comprender"

Sí / No Perceptible NP campo referencial HAPV

$\begin{array}{llllllll}\text { preparar } & \text { fe } 29 & \text { fp } 05 & \text { ft } 34 & \text { df } 24 & \text { df } \% & \text { C480 } & \text { rn CV06 }\end{array}$

acepciones

CP Instruir.

contextos

habla culta: "El ejército debe de buscar, fomentar y preparar [a] los profesionistas que él necesita".

habla popular: "Y más "par'» [para] esos estudios ya elevados, ella «s'» [se] tiene que preparar mejor".

Si / No Perceptible $N p$ campo referencial SOED

regalar fo 17 fp 05 ft 22 df 12 df\% C240 rn CV11

acepciones

CP Obsequiar.

contextos

habla culta: "Le regalamos unas... este... turquesas y se las regalamos muy graciosamente".

habla popular: "Ya ve usted que andan "orita" con criaturas, y tenemos que regalar hasta el gatito: tenemos que regalarlo".

Sí / No Perceptible NP campo referencial SRIN

$\begin{array}{llllllll}\text { sentir } & \text { fe } 42 & \text { fp } 24 & \text { ft } 66 & \text { df } 18 & \text { df\% } & \text { C075 } & \text { on CV25 }\end{array}$

acepciones

c Suponer, imaginar; P Tener una sensación o impresión.

contextos

habla culta: "El comercio en esa época lo sentía yo como una cosa sin importancia".

habla popular: "Cuando yo sintiera que se sentía tristecito, o algo así, le daba media aspirina".

Sí / No Perceptible NP campo referencial HAPV

$\begin{array}{llllllll}\text { servir } & \text { fc } 15 & \text { fp } 03 & \text { ft } 18 & \text { df } 12 & \text { df } \% & \text { C } 400 & \text { rn CV10 }\end{array}$

acepciones

CP Ser útil.

contextos

habla culta: "[Son] materias básicas que le sirven tanto al personal civil como al militar".

habla popular: "Y lo bueno es del coche, que... "pus" [pues] . . sirve muchas veces de mucho".

Sí / No Perceptible NP campo referencial SRIN

$$
\begin{aligned}
& \begin{array}{llllllll}
\text { tratar } & \text { fe } 26 & \text { fp } 16 & \text { ft } 42 & \text { df } 10 & \text { df } \% & \text { C062 } & \text { rn CV27 }
\end{array} \\
& \text { acepciones } \\
& \text { CP Intentar, procurar. }
\end{aligned}
$$


contextos

habla culta: "Pero, sí, tratarlos de ayudar lo más posible en las dos cosas ¿no?"

habla popular: "Traté de localizarte a ti y a él, y hasta que logré..."

Sí / No Perceptible NP campo referencial SRIN

valer fo $16 \quad \mathrm{fp} 03$ ft 19 df 13 df\% C433 $\mathrm{maV08}$

acepciones

CP Tener un valor, un costo.

contextos

habla culta: "Pero él créa que valian cinco pesos. Porque tú también le contaste que no valian nada".

habla popular: "Si trae cien manzanas una caja, y le vale a "usté ciento ochenta "pes's", sale la manzana, desde allá, a dos".

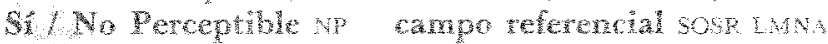

$\mathrm{ANEXOS}$

HABLA POPULAR: SUSTANTIVOS

$\begin{array}{llllllll}\text { agua fo } 09 & \text { fp } 25 & \text { ft } 34 & \text { df } 16 & \text { df } \% & \text { P117 } & \text { in PS20 }\end{array}$

\section{acepciones}

$\mathrm{PC}$ Líquido incoloro, inodoro e insípido.

contextos

habla culta: "En la noche, bajaban a tomar agua de un río".

habla popular: "Hay veces que lo bañamos con agua fria".

Si/ No perceptible $\mathrm{SP}$ campo referencial LMA

animal fe 06 p 10 f 16 df 04 dr\% P066 m PS28

acepcrones

PC Bestia, ser irracional.

contextos

habla cula: "Así que monto [al caballo] hasta que me lleva a casa, ifijese si es listo el animal!"s

habla popular: "Es que "to" estos animales tienen los colmillos muy hudos".

Si / No Perceptible SP campo referencial LMNA

camión fe 04 fp 29 ft 33 df 25 df $\%$ P625 rn PS07

acepciones

PC Vehículo de pasajeros, autobús.

contextos

habla culta: "[lba] agarrado el pobre hombre ahí, de un tubo del camión sufriendo la... pisotones".

habla popular: "Como se vienen colgados las gentes, a mí me ha tocado que no me he podido subir al camión".

Sí / No Perceptible sP campo referencial SOSR LMNA

campeonato fc 00 fp 18 ft 18 df 18 df $\%$ P100+ rn PS24 
acepciones

p En los deportes, ciclo o temporadá.

contextos

habla popular: "Casi nada más perdió un partido en todo el campeonato".

Sí / No Berceptible NP campo referencial SESP

campo fo 06 fp 14 fit 20 df 08 df\% P133 m PS19

acepciones

P Lugar donde se practica un deporte como el futbol; C Zona, espacio no urbano.

contextos

babla culta: "Expuso su vidu en los onmos de batalla".

habla popular: "Son... este... tumpos prestados por los equipos integrantes de la liga [de futbol]. Ksos .. upsu paesl son prestados nada más ¿no?

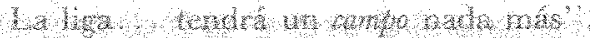

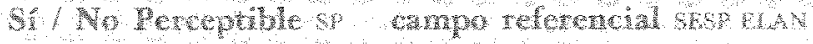

cancion fo 01 fo 38 sit 39 af 37 dec 93700 mPS01

acepeiones

Po Composición musical que se canta.

contextos

habla culta: "Tengo muchas cosas: cancioncitas, juegos digitales; las bases, sobre todo, de cómo educar a un niño".

habla popular: "CCómo te salió la inspiración de la canción que nosotros te vamos a grabar?"

Sí / No Perceptible SF campo referencial SESP

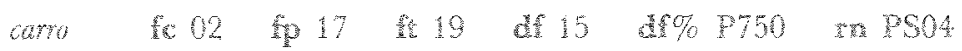

acepciones

p Vehículo de carga, camión; A Automóvil.

contextos

hablia culta: "No le pones los seguros al carro?"

habla popular: "Vende la piedra por viajes... Sí. O seá, cada viaje de... de carro".

Sî/ No Perceptible sp campo referencial SOSR LMNA

chamaco fo 03 fp 25 ft 28 df 22 df\% P733 in PS05

acepciones

PC Muchacho.

contextos

habla culta: "Lo vamos a tener que hacer, ahora también por los chamacos". habla popular: "En realidad, bastante hacia el chamaco con saber leer y escribir".

Sí / No Perceptible sp campo referencial HMNO

chiquillo fe 03 fp 24 ft 27 df 21 dfo P700 rm PS06

acepciones

PC Niño.

contextos 
habla culta: "La escuela de los chiquillos está aquí a dos cuadras".

habla popular: "Era un chiquillo muy "pelionero", inquieto, travieso; brincaba aquí, brincaba allá".

Sí / No Perceptible sP campo referencial HMNO

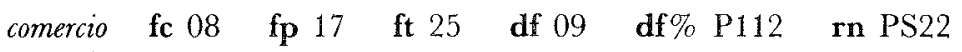

acepciones

P Compra venta de mercancías; C Carrera, materia de estudio.

contextos

habla culta: "Lo mismo pude haber ido a ingeniería que a comercio".

habla popular: "Ya desde esa época "p'" acá, pues ya mi negocio es el comercio".

Sí / No Perceptible NP campo referencial SOSR

compañero fo 07 fp 17 ft 24 af 10 df\% p142 tros P18

acepciones

PC Camarada, amigo.

contextos

habla culta: "Mi jefe es muy simpático, mis compañeros de trabajo me adoran'".

habla popular: "Yo no puedo pensar lo que usted está pensando, ni voy a pensar lo que acá, el compañero, está pensando".

Sí / No Perceptible SP campo referencial SRIN

culpa fc $06 \quad$ fp 12 ft 18 df $06 \quad$ df\% $\%$ P100 $\quad$ rn PS24

acepciones

PC Falta, delito.

contextos

habla culta: "Yo no le echo la culpa a nadie de lo que hago".

habla popular: "Porque hay veces que, cuando el hombre no tiene la culpa, la tiene la mujer".

Sí / No Perceptible NP campo referencial HAPV

domingo fc 07 fp 24 ff 31 df 17 df $\%$ P242 rn PS13

acepciones

PC Día de la semana.

contextos

habla culta: "No es de los que va a misa todos los domingos".

habla popular: "Yo, el domingo, es el día que compro. Y yo veo que siempre hay más gente".

Sí / No Perceptible NP campo referencial TRTM

equipo $\begin{array}{lllllll}\text { fc } 07 & \text { fp } 23 & \text { ft } 30 & \text { df } 16 & \text { df\% } & \text { P228 } & \text { rn PS14 }\end{array}$

acepciones

PC Grupo de jugadores.

contextos

habla culta: "Estaba yo en el equipo, y llegaba a los partidos a jugar inmediatamente".

habla popular: "Terminamos empatados en tercer lugar con otro equipo". 
Sí / No Perceptible SP campo referencial SESP

$\begin{array}{llllllll}\text { grupo fc } 05 & \text { fp } 13 & \text { ft } 18 & \text { df } 08 & \text { df } \% & \text { P160 } & \text { rn PS16 }\end{array}$ acepciones

$\mathrm{PC}$ Conjunto de personas o cosas.

contextos

habla culta: "No pueden alternar con el grupo de solteras que alternaban antes".

habla popular: " "Pus" es como compañeros de grupo que "semos" [somos]". Sí / No Perceptible sP campo referencial skIN

gruta fo 05 fp 20 ft 25 df 15 df $\%$ P300 m PS12

acepciones

PC Cavidad natural que se visita.

contextos

habla culta: "Entonces, está la gruta y junto hicieron una capilla".

habla popular: "Voy con mis papás [... a] ellos les gusta ir a yer cosas aś, raras, digamos. Porque, pues... las grutas este... pues son así, cosas que... que digo se siente cierta sensación al entrar ahí".

Sí / No Perceptible sP campo referencial SESP ELAN

$\begin{array}{llllllll}\text { kilo } & \text { fc } 01 & \text { fp } 32 & \text { ft } 33 & \text { df } 31 & \text { df } \% & \text { P3100 } & \text { ra PS02 }\end{array}$

acepciones

PC Medida de peso equivalente a 1000 gramos.

contextos

habla culta: "No valen nada; si las compro por kilo".

habla popular: "Precisamente en la televisión pusieron "qu'" el ajo estaba a dos pesos el kilo".

Sí / No Perceptible SP campo referencial SOSR

kilometro foc 03 ip 13 ft 16 df 10 dr\% P333 rn PSO9

acepciones

PC Medida de distancia equivalente a 1000 metros.

contextos

habla culta: "Mi suegro, por ejemplo, ahorita corre tres kilómetros y medio". habia popular: "Son dos kilómeiros que tiene uno que caminar".

Sí / No Perceptible SP campo referencial ELAN

maestro fc 03 fp $34 \quad$ ft 37 df $31 \quad$ df\% P1033 rn PS03

acepciones

PC Profesor.

contextos

habla culta: "Al maestro uno le dice: "Mire: esto así se hace"”.

habla popular: "Si hay un maestro y eso que les "esplique» [explique] y eso, ¡qué mejor!"

Sí / No Perceptible SP campo referencial SCED SOSR

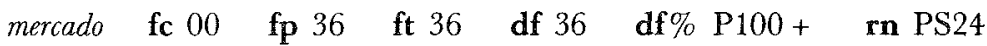

acepciones 
P Lugar donde se compra y se vende.

contextos

habla popular: "Desde que nos metimos al mercado, duramos «sieti» años para componernos, para nivelar la venta".

Si / No Perceptible SP campo referencial SOSR ELAN

miedo fe 07 fp 15 ff 22 df 08 df\% P114 rn PS21

acepciones

po Temor.

contextos

habla culta: "Yo no sé manejar. Quiero aprender pero, por un lado, the da un poco de miedo".

labla popular: "Y ahí me daba reteharto miedo. Estaba bien oscuro".

Si / No Perceptible NP campo referencial HAPV

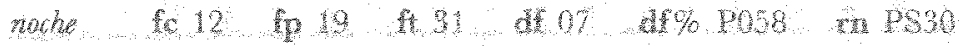

acepciones

po Parte del día en la que no hay luz del sol.

contextos

habla culta: "Cuando llego, me baño, descanso toda la noche".

habla popular: "Estoy aquí lavando hasta las ocho de la noche".

Sí / No Perceptible SP campo referencial TRTM

$\begin{array}{llllllll}\text { novio } & \text { fc } 09 & \text { fp } 22 & \text { ft } 31 & \text { df } 13 & \text { df } \% & \text { P144 } & \text { rn PS17 }\end{array}$

acepciones

PC Pretendiente.

contextos

habla culta: "Yo también tengo unas [cartas] guardadas. . Y haz de cuenta: como cartas de novio; como se usaban antes las cartas de los novios. Así, así tengo".

habla popular: "Ya enpecé a trabajar, ya de... ya grande. "Tons" [entonces] tuve un nowio. Lo quería mucho; "m" entusiasmé mucho con el".

Si / No Perceptible SP campo referencial SRIN

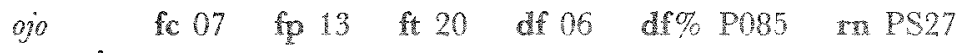

acepciones

PC Órgano de la vista.

contextos

habla culta: "Las películas de terror, bueno, yo no las soporto. Me paso toda la película tapada de los ojos".

habla popular: "Mi suegra... él... mi cuñada son de ojos verdes. Pero de mis hijos, nadie".

Sí/ No Perceptible SP campo referencial HCRP

perro fc $04 \quad f$ f 12 ft 16 df 08 df\% $\quad$ P200 $\quad$ rn PS15

acepciones

PC Can, animal doméstico.

contextos 
habla culta: "Cuántas personas solteras, ese amor, ¿a quién se lo dedican? A un gato, a un perro".

habla popular: "Pero que dicen "qu'" el [que el] perro [que estaba en la cueva) salió a la superficie, y que ladraba".

Sí/ No Perceptible SP campo referencial LMNA

peso fo 19 fp 79 ft 98 df 60 df\% P315 rn PS11

acepciones

PC Unidad monetaria.

contextos

habla culra: "Le regalé un peso y... luego luego nos hicimos de conversación".

habla popular: "Dábamos hasta "veint" cinco nopales por un peso".

Sí/ No Perceptible SP campo referencial sosR LMNA

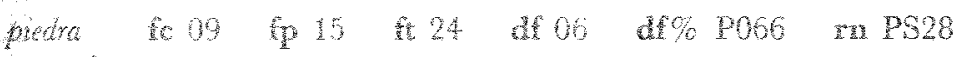

acepciones

Po Porción de roca.

contextos

habla culta: "La entrada de la igiesia... está reducido [sic] en tal forma la entrada con piedras, que sólo puede entrar una persona de frente".

habla popular: "La forma que tiene la piedra, que se ha ido formando con las gotas de agua que se filtra a través de las rocas".

Sí / No Perceptible SP campo referencial LMNA

prueba fc 08 fp 17 ft 25 af 09 dr\% P112 rn PS22

acepciones

PC Comprobacion, examen.

contextos

habla culta: "Pero cuando usted ya llegue al límire que significa la no tolerancia más, entonces venga a verme y tráigame estas pruebas".

habla popular: "Si gustas, vámonos poniendo a prueba".

Sí / No Perceptible NP campo referencial SCED

kubblo fo 05 fp 21 ft 26 df 16 df\% P320 in PS10

acepciones

PC Lugar con pocas casas, ciudad pequeña.

contextos

habla culta: "Para progresar un pueblo... deben de trabajar todos".

habla popular: "Ese fublo "stán [está] bastante retirado".

Sí / No Perceptible SP campo referencial ELAN

semana fic 04 fp 25 fit 29 df 21 dr\% P525 rin PS08

acepciones

PC Periodo de siete días.

contextos

habla culta: "Yo voy una vez a la semana".

habla popular: "Lunes, martes... se siguió la semana".

Sí/ No Perceptible NP campo referencial TRTM 
habla culta: "Cuántas personas solteras, ese amor, ¿a quién se lo dedican? A un gato, a un perro".

habla popular: "Pero que dicen "qu'" el [que el] perro [que estaba en la cueval salió a la superficie, y que ladraba".

Si / No Perceptible SP campo referencial LMNA

peso fc 19 fp 79 ft 98 df 60 df\% 3315 rn PS11

acepciones

- PC Unidad monetaria.

contextos

habla culta: "Le regalé un pesa y... huego luego nos hicimos de conversactón".

habla popular: "Dábarnos hasta "veint" cinco nopales por un peso".

Si/ Wo Perceptible SP campo referencial SOSR LMNA

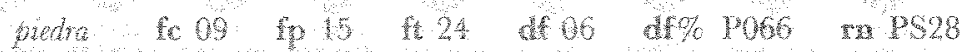

actepciones

po Porción de roca.

conkextos

habla culta: "La entrada de la iglesia... está reducido [sic] en tal forma la entrada con piedras, que sólo puede entrar una persona de frente".

habla popular: "La forma que tiene la piedra, que se ha ido formando con las gotas de agua que se filtra a través de las rocas".

Sí / No Perceptible SP campo referencial LMNA

prueba fic 08 fp 17 fic 25 df 09 df\% P112 In PS22

acepciones

Po Comprobación, examen.

contextos

dabla culta: "Pero cuando usted ya llegue al límite que significa la no tolerancia más, enconces venga a verme y trágame estas prubas".

habla popular: "Si gustas, vámonos poniendo a prueba".

Si / No Perceptible NP campo referencial SowD

puebio fc05 fp 21 ft 26 df 16 df\% P320 rn PS10

acepciones

po Lugar con pocas casas, ciudad pequeña.

contextos

habla cultal: "Para progresar un pueblo... deben de trabajar todos".

habla popular: "Ese pueblo "stá" [está] bastante retirado".

Sí / No Perceptible sp campo referencial LLAN

semana fo 04 fp 25 ft 29 af 21 dfo P525 rn PS08

acepciones

Po Periodo de siete días.

contextos

habla culta: "Yo voy una vez a la semana".

habla popular: "Lunes, martes... se siguió la semana".

Si / Wo Perceptible NP campo referencial TRTM 
ANEXO 4

HABIAA POPULAR: VERBOS

abrir fo $06 \quad \mathrm{fp} 19$ ft 25 df 13 df\% $\quad$ P216 $\quad$ rn PV11

acepciones

PC Hacer que algo no esté cerrado.

contextos

habla culta: "Él abrió la puerta, cuando los fuimos a ver".

habla popular: "[El negocio] se abre a las nueve [de la mañana] y se cierra a las ocho y media [de la noche]".

Sí/ No Perceptible sp campo referencial lanA

agarrar fe 08 fp 39 ft 47 df 31 df\% P387 rn PV07

acepciones

Pe Tomar, anir algo.

contextos

habla culta: "Si me tomaba la mano, ados se parabar de puntas ipor que le agarraba la mano?"

habla popular: "Mejor, mejor agaro un carro de rueditas, y voy a juntar" papel".

Sí / No Perceptible sp campo referencial LMNA

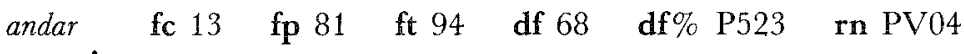

acepciones

PC (en perífrasis) Hacer algo habitualmente.

contextos

habla culta: "No tengo por qué andarle rogando".

habla popular: "Los que andan dando boletos aquí, andon engañando a la gente".

Sí / No Perceptible NP campo referencial SOSR

ayudar foll ip 22 ft 33 af 11 dr\% P100 rn PV19

acepciones

PC Auxiliar, dar ayuda.

contextos

habla culta: "Él era un hombre muy liberal, inclusive él me ayudó a que yo revalidara mi Secundaria".

habla popular: "Entonces, como dice la maestra, hay que ayudarnos uno y otro, ¿no?"

Sí / No Perceptible No campo referencial SRIN

bajar fo 06 fp 34 fo 40 df 28 df\% $\mathrm{P} 466$ rn PV05

acepciones

PC Ir a un lugar más bajo, descender.

contextos

habla culta: "En la noche, bajaban a tomar agua de un río, que pasaba por Jerusalén".

habla popular: "Nada más baja usted los domingos a... a la plaza, y ya".

Sí / No Perceptible SP campo referencial HCRP 
buscar fc 15 fp 25 ft 40 df 10 df\% P066 rn PV24

acepciones

PC Hacer algo para encontrar algo o a alguien.

contextos

habla culta: "Lo que tienes que buscar es que la mujer, mientras es soltera, mientras es independiente, puede desarrollarse en cualquier medio".

habla popular: "La niña siempre es más... más sensible: busca el modo de no... de no herir [a la gente]".

Sí / No Perceptible NP campo referencial SRIN

$\begin{array}{llllllll}\text { comer fe } 17 & \text { fp } 47 & \text { ft } 64 & \text { df } 30 & \text { dr\% } & \text { P176 } & \text { rn PV12 }\end{array}$

acepciones

PC Ingerir alimentos.

contextos

habla culta. "Ahorita ya duerne on el Centmo Olimpico, y sme y desayuna alla".

habla popular: "También te imaginas cuánta porqueria no han de comer en la calle".

Sí / No Perceptible Sp campo referencial HCRP LMNA

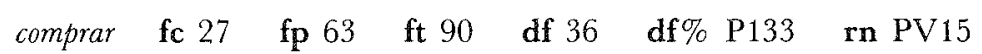

acepciones

PC Adquirir.

contextos

habla culta: "Esas transparencias las compré en el museo del Cairo, en Luxor y, en Carnak".

habla popular: "Ya al final de campeonato se compran los trofeos".

Sî / No Perceptible SP campo referencial SOSR

explicar fc 08 fp 20 ft 28 df 12 df\% P150 $\quad$ rn PV13

acepciones

PC Dar explicación, hacer entender.

\section{contextos}

habla culta: "De haber ciertas cosas que, si el niño no las entiende, no tiene uno por qué explicárselas".

habla popular: "Pues si hay un maestro y eso, que les "espliquen [explique] y eso, ¡"pos" qué mejor!"

Sí / No Perceptible NP campo referencial SCED

explorar fc 00 fp 17 ft 17 df 17 df\% P100+ rn PV19

acepciones

p Indagar, sobre todo en lugares naturales.

contextos

habla popular: "No sé de qué país o sea, que no era de aquí, que andaba "esplorando" [explorando] ahí las grutas con un perro".

Sí / No Perceptible SP campo referencial SESP

formar fe $05 \quad$ fp $16 \quad$ ft $21 \quad$ df $11 \quad$ df $\%$ P220 $\quad$ rn PV 10

acepciones 
PC Dar forma, hacer.

contextos

habla culta: "Entonces, se [sic] tiende a formarse ahí reumatismos y esas cosas".

habla popular: "Se forma un lodo, un lodo muy peligroso "par" uno".

Sí/ No Perceptible sp campo referencial LMNA

levantarse fe 02, fp 18 ft 20 af 16 df\% $F 800$ m PV03

acepciones

p Levantarse, despertarse; $c$ Alzar, subir.

contextos

habla culta: "Para que un juez te grite y te levante la mano, se necesita que sea. . una cosa inusitada".

habla popular. "Se acuesta tho algo nochecto, pero ya esta un acostum-

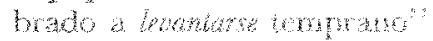

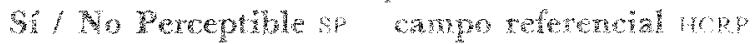

pagar ic 08 fp 35 fr 43 de 27 df\% $\$ 337$ m PVog

acepciones

PC Hacer un pago, saldar una deuda.

contextos

habla culta: "Pagamos ciento cinco cada uno, entre los dos".

habla popular: "Ahí nos pagan la mitad de lo que cuesta el carro".

Sí / No Perceptible SP campo referencial SOSR

partir fo 02 fp 19 fo 21 df 17 df\% P850 rn PV02

acepciones

p Cortar algo en partes; c Iniciar, basarse.

contextos

habla rulta: "Si estás proviendo de un primipio cristiann an pued arepta. una situacion as".

kabla popular: "Nomás deberías de ir a parior las piedras que yo paro"

Si / No Perceptible SP campo reterencial SOSR IMNA

platicar fo 16 fp 39 ff 55 df 23 df\% P143 rm PV14

acepciones

PC Charlar, conversar.

contextos

habla culta: "Desde luego yo me muero de la aburrición si platico con un taxista una hora. ¿Qué le platico? ¿Qué le cuento?"

habla popular: "Tenemos que piaticamos uno y otro, $¿$ no?, contarnos de nuestras cosas que hacemos".

Sí / No Perceptible NP campo referencial SRIN

preguntar fc 08 fp 17 ft 25 df 11 df\% P112 rn PV17

acepciones

PC Interrogar, hacer preguntas.

contextos 
Thabla culta: "Solamente cuando pregumian por el o que le tengo que pasar algin recedo, le hablo".

hable pormellar: "Ella me va a preguntar por qué no me gusta el cine... A ver, preguzinteme".

Sâ / No Perceptible NY campo referencial SRIN

quitar fo 10 fp 19 ft 29 df 09 dr\% P090 rn PV21

acepciones

PC: Tomar algo, apartarlo, separarlo.

contextos

habla culta: "Lo habian robado al llegar a la aduana, que porque le habian quitado, setertia y cinco pesos".

habla popular: "Van a quitarnos de aqui".

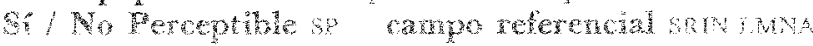

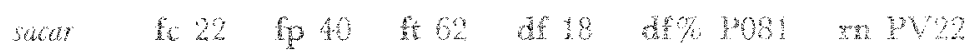

acepciones

pC Obtener, conseguir algo de alguien.

contextos

habla culta: "Noventa por ciento está podrido, de que no ve más que la forma de sacar dinero con... haciendo negocios".

habla popular: "Porque «ora", hay "ves's» [veces] que no... no saca uno ni "pa" [para] las tortillas, que están tan caras".

Sí / No Perceptible NP campo referencial SOSR SRIN

Eerminar fe $10 \quad \mathrm{fp} 21$ ft 31 df 11 af $\%$ P110 in PV18

acepciones

re Tinalizar, concluir aso, sobre todo w relación an los e.tudiog.

contextos

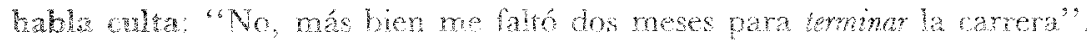

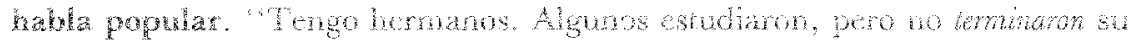
primaria, porque fuevon de mala cabeza"

ST/ Ra Percoptible NP campo teferencial som

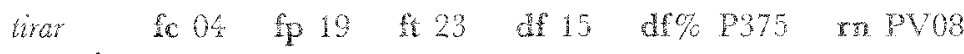

acepciones

po Arrojar algo.

contextos

habla culta: "Esto es una lluvia que viene de una bomba que han tirado los americanos".

habla popular: "Tenemos nuestros líos con las señoras que tiran la basura en la calle"

Sí / No Perceptible sp campo referencial LMNA

tocar fc 07 fp 39 ft 46 df 32 df\% P457 ren PV06

acepciones

PC Producir música mediante un instrumento.

contextos 
habla culta: "Las enseñaban que a bordar, que a tocar piano y cositas por el estilo".

habla popular: "Te oigo a ti tocar la guitarra tan bien, que hasta hasta me da envidia".

Sí / No Perceptible Sp campo referencial SESP

vender fc $06 \quad$ fp $84 \quad$ ft $90 \quad$ df 78 df\% P1300 $\quad$ rn PV01

acepciones

PC Hacer ventas.

contextos

habla culta: "Pinta para vender su cuadro en cien o doscientos dólares".

habla popular: "Por ejemplo, el carro... el carro lo venden en... en treinta pesos, [y] a ellos les dan quince".

Sí / No Perceptible SP campo referencial SOSE

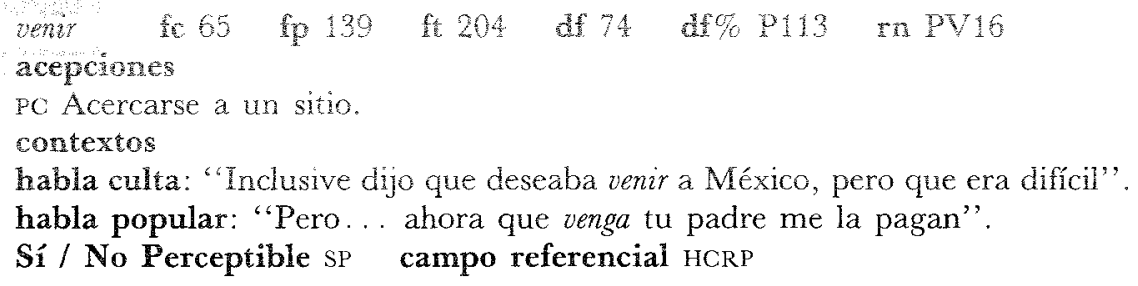

